\title{
TF-Cluster: A pipeline for identifying functionally coordinated transcription factors via network decomposition of the shared coexpression connectivity matrix (SCCM)
}

Jeff $\mathrm{Nie}^{1 \dagger}$, Ron Stewart ${ }^{1 \dagger}$, Hang Zhang ${ }^{6}$, James A Thomson ${ }^{1,2,3,9}$, Fang Ruan ${ }^{7}$, Xiaoqi Cui ${ }^{5}$ and Hairong Wei ${ }^{4,8^{*}}$

\begin{abstract}
Background: Identifying the key transcription factors (TFs) controlling a biological process is the first step toward a better understanding of underpinning regulatory mechanisms. However, due to the involvement of a large number of genes and complex interactions in gene regulatory networks, identifying TFs involved in a biological process remains particularly difficult. The challenges include: (1) Most eukaryotic genomes encode thousands of TFs, which are organized in gene families of various sizes and in many cases with poor sequence conservation, making it difficult to recognize TFs for a biological process; (2) Transcription usually involves several hundred genes that generate a combination of intrinsic noise from upstream signaling networks and lead to fluctuations in transcription; (3) A TF can function in different cell types or developmental stages. Currently, the methods available for identifying TFs involved in biological processes are still very scarce, and the development of novel, more powerful methods is desperately needed.

Results: We developed a computational pipeline called TF-Cluster for identifying functionally coordinated TFs in two steps: (1) Construction of a shared coexpression connectivity matrix (SCCM), in which each entry represents the number of shared coexpressed genes between two TFs. This sparse and symmetric matrix embodies a new concept of coexpression networks in which genes are associated in the context of other shared coexpressed genes; (2) Decomposition of the SCCM using a novel heuristic algorithm termed "Triple-Link", which searches the highest connectivity in the SCCM, and then uses two connected TF as a primer for growing a TF cluster with a number of linking criteria. We applied TF-Cluster to microarray data from human stem cells and Arabidopsis roots, and then demonstrated that many of the resulting TF clusters contain functionally coordinated TFs that, based on existing literature, accurately represent a biological process of interest.
\end{abstract}

Conclusions: TF-Cluster can be used to identify a set of TFs controlling a biological process of interest from gene expression data. Its high accuracy in recognizing true positive TFs involved in a biological process makes it extremely valuable in building core GRNs controlling a biological process. The pipeline implemented in Perl can be installed in various platforms.

\footnotetext{
* Correspondence: hairong@mtu.edu

+ Contributed equally

${ }^{4}$ School of Forest Resources and Environmental Science, Michigan

Technological University, 1400 Townsend Drive, Houghton, MI 49931, USA

Full list of author information is available at the end of the article
} 


\section{Background}

Identifying the TFs potentially involved in a biological process is critical to unveiling regulatory mechanisms. Examples of the importance of identifying a small list of potentially crucial transcription factors include reprogramming somatic cells to a pluripotent state $[1,2]$, the transdifferentiation of cells via forced TF expression [3] and genetic engineering of plants for increased productivity and adaptability[4]. Except for TF-finder [5], there is currently no methods or software specifically tailored to identifying TFs from expression data. Although some very well-performing network construction methods, for instance, CLR [6], NIR[7] and ARACNE [8], can be used to identify TFs from expression data, these methods are strictly TF-target oriented and output a wellconnected regulatory network. Given that microarray data only measure a small component of the interacting variables in a genetic regulatory network[9] and that some portions of the nonlinear relationships between TF-targets are difficult to simulate and predict $[10,11]$, identifying via TF-target modeling a short list of crucial TFs controlling biological processes in either mammals and plants is inefficient. As prior knowledge of target genes often do not exist, there is a need to develop new approaches for recognizing a short list of TFs controlling a biological process

With few sequence features among TF family that can be used to infer the functions of TFs, effective methods for identifying TFs that control a biological process have to rely on gene expression data or other datasets. Due to the challenges in generating time-series data with small intervals for higher plants and mammalian models, developing new methods that are applicable to compendium data sets pooled from multiple microarray experiments or public data resources is very useful. In this study, we collected microarray gene expression data from the same tissue types under similar conditions from multiple experiments to facilitate method development.

Genome-wide microarray data have shown that the coordination of functionally associated TFs is very noisy. This is because transcription is very complicated, with at least several TFs involved in establishing the transcriptional activity of any particular gene. An early study showed that transcription noise is partly due to a combination of variability in upstream signaling [12]. In addition, transcription for a particular gene can occur in bursts and can fluctuate, sometimes (but not always) in synchrony with biological processes such as the cell cycle [13] somitogenesis [14], or slow transitions between promoter states [12]. The abundance of TFs for a given gene or the number of transcription-factor binding sites within its promoter or enhancer can affect the amplitude, periodicity, and duration of transcriptional bursts [15]. In addition, the nucleosome positions and activities of chromatin remodelers can also cause transcriptional perturbation by the interconversion of a promoter between active and inactive states [16,17]. Moreover, chromatin domains also contribute to transcriptional variability; a change in the chromosome position of a gene affects not only its expression level but also its noisiness [18]. It has been shown that multiple copies of a given gene exhibit coordinated bursting when integrated in tandem, but exhibit uncorrelated responses when integrated at different chromosomal positions [19]. Noise in gene expression can disturb or impair the correlation and thus make the identification of coordinated TFs more challenging. In this regard, we should not anticipate that the TFs functioning in coordination have a perfect correlation or coordination and the mathematical methods that emphasize approximate "correlations" may recognize the functionally coordinated TFs more efficiently.

In this study, we developed a novel approach for identifying TFs involved in a biological process by building a conceptually new coexpression network represented by SCCM and then decomposing it into multiple subnetworks (or subgraphs) using Triple-Link, a heuristic algorithm that works as follows: it first searches all connected node pairs (genes) in the SCCM, and identify the one with highest connectivity, which is used as a primer for growing into a TF cluster. All TFs that are subsequently joined in need to have at least three significant connectivities to the TFs already in the cluster, with the exception of the third TFs that is required to have two. The cluster stops growing until there are no more nodes (TFs) meeting the requirement. A TF cluster is then produced. All TFs in this cluster are removed from the TF pool and SCCM matrix, and they do not participate in the next round of analysis. This process is repeatedly executed until all TFs are placed into clusters. The SCCM can be broken down into many subnetwork graphs because it is sparse and symmetric with both dimensions containing the same set of TFs. For such a graph, a few other graph clustering methods, including Markov Cluster Algorithm (MCL) [20] and affinity propagation (AP) [21], can also be applied to decompose it into multiple subgraphs. However, these methods were not developed specifically for decomposing the coexpression network we built in this study and thus may not produce outputs optimal for biological interpretation. In contrast to our other method TF-Finder [5], TF-Cluster does not require the use of any existing knowledgebase. We applied TF-Cluster to the microarray data from human embryonic stem cells during a transition from the undifferentiated ES state to a 
variety of differentiated states, and also applied to microarray data from Arabidopsis roots under salt stress. TF-Cluster recovers non-overlapping clusters containing important TFs recently identified as involved in controlling the pluripotency of human embryonic stem (hES) cells, human neural development and multidirectional differentiation, as well as Arabidopsis root growth and development in response to salt stress. In this study, functionally coordinated TFs refer to a group of TFs that are loosely coordinated in expression profiles as measured by the number of shared coexpressed genes. We postulate that these TFs control multiple facets of a biological process independently or combinatorially by controlling a set of target genes that may function in various subcellular components, in different cell types, or even in different organs if only they can function coordinately in time. As a result, the identified $\mathrm{TF}$ in the same cluster may not bind to the same group of target genes though it is very likely that a subset of TFs may bind to a subset of targets.

\section{Results}

Using the pipeline containing Spearman rank correlation, the coexpression analysis was applied to both human and Arabidopsis data sets, and a SCCM was built for human and Arabidopsis respectively. We then decomposed the SCCM into subgraphs (clusters) with the Triple-Link algorithm. Since TF clustering was always initiated with a pair of TFs with maximal connectivity, a significant and also well-coordinated cluster is usually extracted earlier than a less significant one. To demonstrate the efficiency of this package and the Triple-Link algorithm, we examined some TF clusters derived from human and Arabidopsis data.

\section{Identification of functionally coordinated TFs during differentiation of human embryonic stem cells}

As described in Methods, the microarray data set for human stem cells was collected from 17 experiments in which hES cells were treated with various differentiation reagents. Therefore, these datasets include states involved in many regulatory events underpinning pluripotency, such as ES maintenance, exiting the pluripotent state, and differentiation. If TF-Cluster is adequately efficient, we anticipated that those TFs involved in pluripotency would be identified at an early stage of execution. In fact, the first cluster identified was the one containing many known pluripotency-controlling transcription factors (see Table 1).

\section{TF cluster indentified with pluripotency of human embryonic stem cells}

To demonstrate that this cluster is strongly correlated with human embryonic stem cell pluripotency, we examined each gene and the literature support for its involvement with pluripotency. PHC1 is implicated in pluripotency because its expression is repressed with the master pluripotency genes, OCT4 and NANOG, upon differentiation with retinoic acid (RA) [22]. ZFP206 (ZSCAN10) is a TF that controls pluripotency of embryonic stem cells by activating transcription of the OCT4 and NANOG promoters [23,24]. ZNF589, DNMT3A/B and SALL2 have been defined as pluripotency associated factors [25]. A novel DNMT3B splice variant was found to be expressed in pluripotent and cancer cells [26]. ES cells lacking the nucleosome assembly factor HIRA exhibit elevated levels of unbound histones, and the formation of embryoid bodies is accelerated, indicative of the onset of differentiation [27]. Embryoid bodies are aggregates of cells derived from embryonic stem cells. Upon aggregation, differentiation is initiated and the cells begin to recapitulate embryonic development to a limited extent. ETV1 is a direct target of NANOG and OCT4 in ES cells [28,29]. CITED2, as a TF playing key roles in mouse embryonic development, is involved in self-renewal and prevents spontaneous differentiation of E14Tg2a mouse ESC [30]. In addition, CITED2 is an essential regulator in adult hematopoietic stem cells [31]. Although their roles in ES cells are not clearly defined, TRIM 22 and ZIC3 are believed to play a role in ES cells and have been used as ES markers [32].

This suggests that the TF-Cluster method is viable and can easily identify many of the key TFs reported in the literature as controlling the pluripotency of human stem cells. Of the $24 \mathrm{TFs}$ in this cluster, $16(\sim 67 \%)$ have literature support for either being directly involved in the ES network or associated with ES cells. In the case of NANOGP8 and LOC653441, the literature contains evidence of a potential cross-hybridization with probes for known pluripotency regulators NANOG and PHC1 respectively. Although the other eight TFs - CSRP1, HES6, TRIM65, OTX2, FOXA3, ELF4, HOXB4, and ZNF101 - do not currently have supporting evidence, this does not indicate that they are not involved in pluripotency. For instance, HOXB4 has been indicated to play a role in the renewal of hematopoietic stem cells $[33,34]$. We believe future research will provide more clues regarding these particular genes. Nevertheless, our rediscovery of many important TFs involved in pluripotency maintenance using TF-Cluster suggests that it is highly efficient.

Cluster 1 contains three master TFs: Nanog, Sox2, and Oct4, which can bind to 1,330 active genes in stem cell independently or combinatorially. Among the 24 TFs of this cluster, only TRIM22 is bound by these three master TFs as indicated by the CHIP-on-chip data produced in previous study (Boyer, 2005). The same data also indicated that SALL2 is bound by Nanog only but at a 
Table 1 TF cluster identified with pluripotency of human embryonic stem cells

\begin{tabular}{|c|c|c|c|}
\hline Genes & Symbol & Description & Evidence \\
\hline \multicolumn{4}{|c|}{$\begin{array}{l}\text { Cluster 1: TFs control pluripotency renewal of human } \\
\text { stem cells }\end{array}$} \\
\hline NM_024865 & NANOG & Nanog homeobox & [96] \\
\hline BC099704 & NANOGP8 & Nanog homeobox pseudogene 8 & $\begin{array}{l}\text { Pseudogene with } \\
\text { similarity to Nanog. }\end{array}$ \\
\hline NM_003106 & SOX2 & SRY box 2 & [96] \\
\hline NM_002701 & POU5F1 & POU class 5 homeobox 1 & [96] \\
\hline NM_006892 & DNMT3B & DNS methyltransferase 3 beta & {$[26,97]$} \\
\hline NM_004078 & CSRP1 & cysteine-rich protein & \\
\hline NM_080618 & CTCFL & CCCTC-binding factor (zinc finger protein)-like & {$[98]$} \\
\hline NM_016089 & ZNF589 & Zinc finger 589 & {$[25,32]$} \\
\hline NM_004426 & PHC1 & Polyhomeotic homolog 1 & [22] \\
\hline NM_005407 & SALL2 & SAL2 like & [25] \\
\hline NM_018645 & HES6 & Hairy and enhancer of split 6 & \\
\hline NM_173547 & TRIM65 & Tripartite motif containing 65 & \\
\hline NM_004427 & $\mathrm{PHC2}$ & Polyhomeotic homolog 2 & [99] \\
\hline NM_032805 & ZFP206 & Zinc finger protein 206 (ZSCAN10) & {$[23,24]$} \\
\hline NM_001421 & ELF4 & ETS domain TF & \\
\hline NM_003325 & HIRA & HIR Histone Cell Cycle regulator & {$[100]$} \\
\hline NM_033204 & ZNF101 & Zinc finger protein 101 & \\
\hline BC098403 & ETV1 & ETS variant 1 & {$[28,29]$} \\
\hline NM_006079 & CITED2 & Cbp/p300-interacting transactivator & {$[30,31]$} \\
\hline NM_021728 & OTX2 & Orthodenticle homeobox 2 & \\
\hline NM_024015 & HOXB4 & Homeobox B4 & \\
\hline NM_006074 & TRIM22 & Tripartite motif-containing 22 & [32] \\
\hline XM_929986 & LOC653441 & Similar to polyhomeotic 1-like & $\begin{array}{l}\text { Gene with sequence } \\
\text { similarity to PHC1 }\end{array}$ \\
\hline NM_004497 & FOXA3 & Forkhead box 3 & \\
\hline \multicolumn{4}{|c|}{$\begin{array}{l}\text { Cluster 22: TFs control neural development in earlier } \\
\text { differentiation of human stem cells }\end{array}$} \\
\hline BC008687 & NEUROG1 & Neurogenin 1 & [101] \\
\hline NM_006161 & NEUROG1 & Neurogenin 1 & [101] \\
\hline NM_001965 & EGR4 & Early growth response & \\
\hline NM_033178 & DUX4 & Double homeobox 4 & [38] \\
\hline NM_006732 & FOSB & FBJ oncogene homolog B & [35] \\
\hline NM_003317 & TITF1 & NK2 homeobox 1 & [39] \\
\hline NM_002478 & MYOD1 & myogenic differentiation 1 & {$[43,44]$} \\
\hline NM_006192 & PAX1 & Paired box 1 & {$[36]$} \\
\hline NM_002700 & POU4F3 & POU class 4 homeobox 3 & {$[37]$} \\
\hline BC10493 & POU4F3 & POU class 4 homeobox 3 & {$[37]$} \\
\hline \multicolumn{4}{|c|}{$\begin{array}{l}\text { Cluster 17: TFs control differentiation towards multiple } \\
\text { directions in human stem cells }\end{array}$} \\
\hline NM_001002295 & GATA3 & GATA binding protein 3 & Trophectoderm [45] \\
\hline NM_012258 & HEY1 & $\begin{array}{l}\text { Hairy/enhancer-of-split related with YRPW motif } \\
1\end{array}$ & Trophectoderm [46] \\
\hline NM_001804 & CDX1 & Caudal type homeobox 1 & \\
\hline NM_001430 & EPAS1 & Endothelial PAS domain protein 1 & \\
\hline NM_032638 & GATA2 & GATA binding protein 2 & Trophectoderm [47] \\
\hline
\end{tabular}


Table 1 TF cluster identified with pluripotency of human embryonic stem cells (Continued)

\begin{tabular}{|c|c|c|c|}
\hline NM_030379 & GLI2 & GLI family zinc finger 2 & Mesoderm [48] \\
\hline NM_017410 & HOXC13 & Homeobox C13 & Ectoderm[51] \\
\hline NM_002202 & ISL1 & ISL LIM homeobox 1 & Mesoderm [49] \\
\hline NM_033343 & LHX4 & LIM homeobox 4 & \\
\hline NM_002315 & LMO1 & LIM domain only 1 (rhombotin 1) & \\
\hline NM_005461 & MAFB & $\begin{array}{l}\text { v-maf musculoaponeurotic fibrosarcoma } \\
\text { oncogene Homolog B (avian) }\end{array}$ & Neural [53] \\
\hline NM_002448 & MSX1 & Msh homeobox 1 & \\
\hline NM_002449 & MSX2 & Msh homeobox 2 & Mesoderm[50] \\
\hline NM_175747 & OLIG3 & Oligodendrocyte transcription factor 3 & Neural [54] \\
\hline NM_006099 & PIAS3 & Protein inhibitor of activated STAT, 3 & Neural [55] \\
\hline NM_019854 & PRMT8 & Protein arginine methyltransferase 8 & Neural [56] \\
\hline NM_030567 & PRR7 & Proline rich 7 (synaptic) & [102] \\
\hline $\mathrm{BC} 071571$ & RFX2 & $\begin{array}{l}\text { Regulatory factor X, } 2 \text { (influences HLA class II } \\
\text { expression) }\end{array}$ & \\
\hline NM_003068 & SNAI2 & Snail homolog 2 (Drosophila) & Neural Crest[57] \\
\hline NM_031439 & SOX7 & SRY (sex determining region Y)-box 7 & Endoderm (Parietal) [52] \\
\hline NM_003150 & STAT3 & $\begin{array}{l}\text { Signal transducer and activator of transcription } 3 \\
\text { (acute-phase response factor) }\end{array}$ & \\
\hline NM_003221 & TFAP2B & $\begin{array}{l}\text { Transcription factor AP-2 beta (activating } \\
\text { enhancer binding protein } 2 \text { beta) }\end{array}$ & \\
\hline NM_016267 & VGLL1 & Vestigial like 1 (Drosophila) & \\
\hline NM_007129 & $\mathrm{ZIC2}$ & $\begin{array}{l}\text { Zic family member } 2 \text { (odd-paired homolog, } \\
\text { Drosophila) }\end{array}$ & Neural [103] \\
\hline NM_152320 & ZNF641 & zinc finger protein 641 & \\
\hline
\end{tabular}

location around $6.3 \mathrm{~kb}$ upstream. Nothing else is bound by these three TFs, suggesting the dominance of cooperation and synergy among the genes in a TF cluster. In addition, among these 1,330 active genes, 180 genes are controlled by these three master TFs, indicating that combinatorial control is not employed at a high rate (14\%).

\section{TF cluster controlling neural development}

Among the 189 human microarray data sets we used, about 60 were from early differentiation in which very earlier neural development can be tracked. We showed here that TF-Cluster can be used to identify the TFs controlling earlier neural differentiation. We simply searched a neural development marker, NEUROG1, which is contained in the $22^{\text {nd }}$ cluster. This cluster also contains several other genes involved in neural development (Table 1). Among these genes, NEUROG1 is involved in cortical neuronal differentiation. FOSB functions as a molecular switch underlying long-term neural plasticity [35]. PAX1/E2A double-mutant mice develop non-lethal neural tube defects that resemble human malformations [36]. Although the underlying mechanism is unclear, mutation of POU4F3 causes progressive hearing loss in humans [37]. DUX4 is highly expressed in embryonic neural tube by in situ hybridization [38].
TITF1 is implicated to play a role in the enteric nervous system [39]. MYOD1 is such a solid marker for muscle development [40-42] that its involvement in central neuron development in the brain is sometimes overlooked $[43,44]$. The literature support suggests that $90 \%$ (9 of 10) of the genes in this cluster are involved in neural development, indicating that TF-Cluster is capable of identifying clusters with a cohesive set of TFs that function in a biological process.

\section{TF cluster controlling differentiation towards multiple directions}

The 189 human chips were collected from multiple experiments in which stem cells were treated with different reagents that triggered multiple types of differentiation. Usually the stem cells commit to differentiation at 48 hours upon treatment, and then enter a transition stage followed by further differentiation. We collected our data before 96 hours by which time early stages of differentiation, such as early neural differentiation, may be tracked, but more terminal differentiation to heart, brain, liver, kidney has not yet taken place. This early stage involves the formation of various lineage cells that are still in small quantity. All these various cell types, with no a priori knowledge, make it extremely challenging to interpret many clusters derived from this data 
set. We have shown the identification of the cluster involved in pluripotency renewal and the cluster involved in neural development. If we could identify a TF cluster controlling earlier differentiation towards multiple directions, it is an indication that the TF-Cluster pipeline is sensitive and efficient in identifying TFs from data in a chaotic stage. We examined the outputs and found Cluster 17 contains 24 genes, among which 15 TFs are marker genes for trophectoderm [45-47], mesoderm[48-50], ectoderm[51], endoderm[52] and neural [50,53-57] differentiation (Table 1), clearly indicating that the differentiation of these cell types, from which different organs will be derived later, is well coordinated.

\section{Identification of functionally coordinated TFs during salt stress response of Arabidopsis roots}

The Arabidopsis data sets used in this study were from salt stress microarray experiments on Arabidopsis roots. The same data set was used earlier [5] for identifying the TF regulators that control root growth in response to salt stress. In this study, we were mainly interested in the TFs involved in root growth and abscisic acid (ABA, a hormone induced by salt/water stress) responsive TFs. Therefore, we selectively interpreted a few clusters produced by TF-Cluster. These include Cluster 1, 2,5, 7, and 19, and the genes contained in these clusters are shown in Table 2. The TFs in Cluster 1 seem to function in root hair development. LRL3, for instance, is involved in root hair development [58]. Constitutive expression of RSL4 programmed constitutive root growth, leading to the formation of very long root hairs [59]. RHD6 is involved in the early formation of root hairs from epidermal cells [60,61]. Overexpression of the counterpart of RAP2.11 of barley in Arabidopsis results in root growth tolerance to high salinity [62]. TINY encodes a member of the DREB subfamily A-4 of ERF/AP2 transcription factor family (TINY). The mutant of TINY has short roots[63]. The expression of this gene is induced by ethylene, and appears to stimulate cytokinin biosynthesis. Both affect root growth [63]. FRU mRNA is detected in the outer cell layers of the root and accumulates in response to iron deficiency $[64,65]$. In Cluster $1,83 \%$ of the TFs are involved in root growth. The TFs in Cluster 2 are clearly dominated by these genes known to control the stem cells in root cap (Table 2). We successfully discovered a subset of TFs that coordinately control cap growth and maturation. They include BRN1 [66], BRN2 [66], SMB [67], FEZ [67] TOM7 [68], PTL2 [69] and TCP20 [70], which were recently identified as functioning coordinately in the stem cell niche and periphery tissues in root caps. For instance, FEZ and SMB control the orientation of cell division plane in Arabidopsis root stem cells, where FEZ promotes periclinal, root capforming cell divisions while SMB repress stem cell-like divisions in the root cap daughter cells via negatively regulating FEZ activity. In predivision stem cells FEZ activates expression of its negative regulator, $\mathrm{SMB}$, constituting a feedback loop for controlled switches in cell division planes[67]. Interestingly, these TFs' activities are in concert with the activity of IAA33. Although there is currently no evidence supporting the idea that IAA33 plays a major role in root cap growth, auxin is the major hormone controlling many aspects of root growth and development [71]. In Cluster 2, there are also a few TFs that are involved in lateral root development. We visualize this as a coordinated event that happened near the root cap. The TFs in Cluster 5 are mainly involved in second wall growth and vascular development. These include VND7 [72], VND4 [72], SND2 [73], ADOF2[74], AT1G68810, LBD18 [75], MYB46[76], MYB52[76], MYB103[76], MYB20[76], and MYB54[76]. Some of these TFs have recently been identified to function in a TF interactive subnetwork as evidenced by the cited references and the information therein. In this circumstance, $69 \%$ of the TFs in Cluster 5 are involved in the vascular development. The TFs in Cluster 7 mainly control cell cycle and root growth. For instance, AtXR6 [77], DEL3 [78], and HMG1/2 [79] are involved in cell cycle control and progression. Three growth factors that include AtGRF, 1, 2, and 3, were identified by TF-Cluster. These TFs control growth and morphology although their exact functions in root have not been characterized [80,81]. Ectopic expression of MNP causes growth retardation, aberrant cell division patterns, and loss of meristem activity [82]. Finally PS1 is involved in meiosis and mutation of this gene causes cellular diploidy [83]. For Cluster 7, 89\% of the TFs are associated with cell cycle. Finally, Cluster 19 contains TFs that are involved in ABA signaling or response, an event incurred by water deprivation or salt stress. These TFs include GBF3 [84], ABF4 (Yoshida et al. 2010), ANAC019 [85], ATHB7 [86], ATHB12 [86], ABF3 (Yoshida et al. 2010), RD26[87], MYB102[88]. In this case, $47 \%$ of the TFs are associated with ABA signaling.

\section{The efficiency of Triple-Link in decomposing SCCM network}

Compared to existing graph methods, Markov cluster (MCL) algorithm [20] and affinity propagation (AP) [21], Triple-Link can decompose the SCCM more efficiently and results in biologically interpretable TF clusters. This is demonstrated by the functionally cohesive clusters shown in Table 1 and 2. The clusters resulting from MCL are usually bigger and often contain the genes in the clusters identified by Triple-Link (Table 3). For the two clusters with a size of 6 and 9 identified by Triple-Link as controlling Arabidopsis root growth, MCI identified two clusters with a size of 28 and 14 respectively that are supersets of the TFs identified by Triple-Link (Table 3). For the cluster 
Table 2 Cluster 1, 2, 5, 7 and 19 identified from salt stress data of Arabidopsis roots containing root growth and development

\begin{tabular}{|c|c|c|c|}
\hline Gene & Symbol & Description & Evidence \\
\hline \multicolumn{4}{|c|}{ Cluster 1: TFs control the root hair growth } \\
\hline AT5G58010 & LRL3 & Roothairless1 & [58] \\
\hline AT5G19790 & RAP2.11 & $\begin{array}{l}\text { Ethylene response factor controlling root } \\
\text { growth }\end{array}$ & {$[62]$} \\
\hline AT1G27740 & RSL4 & Postmitotic cell growth in root-hair cells & [59] \\
\hline AT1G66470 & RHD6 & Early root hair formation & {$[60,61]$} \\
\hline AT5G25810 & TINY & ERF/AP2 TF control cell expansion in root & [63] \\
\hline AT2G28160 & FRU & $\begin{array}{l}\text { Regulates iron uptake responses in outer cells } \\
\text { of root }\end{array}$ & {$[64,65]$} \\
\hline \multicolumn{4}{|c|}{ Cluster 2: TFs control root cap development (stem cells of roots) } \\
\hline AT1G33280 & BRN1 & BRN1, SMB control root cap maturation & [66] \\
\hline AT4G10350 & BRN2 & BRN2, SMB control root cap maturation & {$[66]$} \\
\hline AT1G79580 & SMB & FEZ and SMB control root stem cells & {$[67]$} \\
\hline AT5G39820 & ANAC094 & Apical meristem protein, function unknown & {$[59]$} \\
\hline AT1G26870 & FEZ & FEZ and SMB control root stem cells in cap & {$[67]$} \\
\hline AT1G74500 & TOM7 & Embryonic root initiation & {$[68]$} \\
\hline AT3G27010 & TCP20 & Postembryonic cell division in root & [70] \\
\hline AT2G30340 & LBD13 & $\begin{array}{l}\text { Expressed in cells at the adaxial base of lateral } \\
\text { roots }\end{array}$ & [104] \\
\hline AT2G40470 & LBD15 & $\begin{array}{l}\text { Expressed in cells at the adaxial base of lateral } \\
\text { roots }\end{array}$ & [104] \\
\hline AT1G51190 & PLT2 & Control root stem cell activity near cap & {$[69]$} \\
\hline AT1G66350 & RGL1 & Root epidermal differentiation & {$[105]$} \\
\hline AT2G37260 & $\pi \mathrm{T} 2$ & $\begin{array}{l}\text { Differentiation of trichomes and root hairless } \\
\text { cells }\end{array}$ & {$[106]$} \\
\hline AT5G57420 & IAA33 & IAA is involved in root development & {$[107,108]$} \\
\hline AT2G29060 & & scarecrow transcription factor family protein & \\
\hline AT5G07580 & & DNA binding/transcription factor & \\
\hline AT1G21340 & & Dof-type zinc finger DNA-binding protein & \\
\hline AT1G75710 & & $\mathrm{C} 2 \mathrm{H} 2$-like zinc finger protein & \\
\hline AT1G77200 & & $\begin{array}{l}\text { DREB subfamily A-4 of ERF/AP2 transcription } \\
\text { factor }\end{array}$ & \\
\hline
\end{tabular}

Cluster 5: TFs control root vascular development, second wall growth development

\begin{tabular}{|c|c|c|c|}
\hline AT1G71930 & VND7 & Regulates xylem vessel formation & {$[72]$} \\
\hline AT5G12870 & MYB46 & $\begin{array}{l}\text { Target of SND1, control second wall } \\
\text { biosynthesis }\end{array}$ & {$[76]$} \\
\hline AT1G01780 & LIM & LIM domain-containing protein & \\
\hline AT1G12260 & VND4 & $\begin{array}{l}\text { Switches for protoxylem and metaxylem vessel } \\
\text { formation }\end{array}$ & {$[72]$} \\
\hline AT1G17950 & MYB52 & Second wall growth & [109] \\
\hline AT1G63910 & MYB103 & Second wall growth & [109] \\
\hline AT1G66230 & MYB20 & Second wall growth & [109] \\
\hline AT1G68810 & $\mathrm{bHLH}$ & Root vascular initial & {$[110]$} \\
\hline AT1G73410 & MYB54 & Second wall growth & [109] \\
\hline AT2G39830 & DAR2 & DA-1 related, control organ size & {$[111]$} \\
\hline AT2G45420 & LBD18 & Lateral root and tracheary element formation & {$[75]$} \\
\hline AT3G21270 & ADOF2 & Early stages of vascular development & [74] \\
\hline
\end{tabular}


Table 2 Cluster 1, 2, 5, 7 and 19 identified from salt stress data of Arabidopsis roots containing root growth and development (Continued)

\begin{tabular}{|c|c|c|c|}
\hline AT4G00220 & $J\llcorner O$ & $\begin{array}{l}\text { A central regulator of auxin distribution and } \\
\text { signaling in root }\end{array}$ & [112] \\
\hline AT4G28500 & SND2 & Vascular cell differentiation & [73] \\
\hline AT5G66610 & DAR7 & DA-1 related, control organ size & [111] \\
\hline \multicolumn{4}{|c|}{ Cluster 7: TFs control root cell cycle \& growth } \\
\hline AT5G24330 & AtXR6 & Cell cycle regulation of late G1 to S phase & [77] \\
\hline AT3G01330 & DEL3 & Cyclin D/retinoblastoma/E2F pathway & [78] \\
\hline AT2G22840 & AtGRF1 & Growth factor expressed in root & {$[80,81]$} \\
\hline AT2G36400 & AtGRF3 & Growth factor expressed in root & {$[80,81]$} \\
\hline AT4G37740 & AtGRF2 & Growth factor expressed in root & {$[80,81]$} \\
\hline AT3G50870 & MNP & GATA transcription factor & {$[113]$} \\
\hline AT1G34355 & PS1 & Parallel spindle 1 involved in meiosis & [83] \\
\hline AT4G23800 & $\begin{array}{l}\text { HMG1/ } \\
\text { HMG2 }\end{array}$ & High mobile group 1, 2 & [79] \\
\hline AT5G25475 & & Transcription factor B3 family & \\
\hline \multicolumn{4}{|c|}{ TFs control drought stress in response to $A B A$} \\
\hline AT2G46270 & GBF3 & induced by $A B A$ under water deprivation & [84] \\
\hline AT3G19290 & ABF4 & $\begin{array}{l}\text { Regulate ABRE-dependent ABA signaling } \\
\text { involved in drought stress }\end{array}$ & {$[114]$} \\
\hline AT1G21000 & Zinc & zinc-binding family protein & \\
\hline AT1G51140 & bHLH & Drought stress & {$[115]$} \\
\hline AT1G52890 & ANAC019 & $\begin{array}{l}\text { Bind to drought-responsive cis-element in } \\
\text { response to ABA }\end{array}$ & {$[85,87]$} \\
\hline AT1G73730 & EIL3 & Ethylene signaling & [116] \\
\hline AT2G18550 & $\mathrm{HB}-2$ & DNA binding/transcription factor & \\
\hline AT2G46680 & ATHB7 & Growth regulator in response to $A B A$ & {$[86]$} \\
\hline AT3G12980 & HAC5 & $\begin{array}{l}\mathrm{H} 3 / \mathrm{H} 4 \text { histone acetyltransferase/histone } \\
\text { acetyltransferase }\end{array}$ & \\
\hline AT3G61890 & ATHB12 & Growth regulator in response to $A B A$ & {$[86]$} \\
\hline AT4G21440 & MYB102 & ABA-induced protein & {$[88]$} \\
\hline AT4G25480 & DREB1A & Drought stress genes responsive to $A B A$ & \\
\hline AT4G27410 & RD26 & $\begin{array}{l}\text { Transcriptional activator in ABA-mediated } \\
\text { dehydration response }\end{array}$ & {$[87]$} \\
\hline AT4G34000 & ABF3 & $\begin{array}{l}\text { Regulate ABRE-dependent ABA-mediated } \\
\text { dehydration response }\end{array}$ & [114] \\
\hline AT4G37180 & MYB & myb family transcription factor & \\
\hline AT5G04760 & MYB & myb family transcription factor & \\
\hline AT5G47640 & NF-YB2 & $\begin{array}{l}\text { NF-YB2 (NUCLEAR FACTOR Y, SUBUNIT B2); } \\
\text { transcription factor }\end{array}$ & \\
\hline
\end{tabular}

controlling human stem cell pluripotency (Table 1), MCL produced a cluster of 219 TFs (not shown) that again is a superset of all those TFs shown in Table 1. A predicted cluster of this size is usually not valuable for biologists as there are too many entries for experimental validation, and various reprogramming studies $[2,89,90]$ have shown that only a moderate number of TFs are needed to reprogram somatic cells to a pluripotent state. Conversely, AP tends to produce smaller clusters than Triple-Link. For the TF cluster controlling pluripotency, AP produced a cluster of 12 members while Triple-Link produced a cluster of 24 members (Table 1 ). These 12 TFs include NM_001452-FOXF2, NM_002701-POU5F1, NM 004426-PHC1, NM_004427-PHC2 NM_004497-FOXA3, NM_004502-HOXB̈7, NM_006079-CITED2, NM_0248 65-NANOG NM_033204-ZNF101, NM_145238-ZNF31, NM_152629-GLIS3, and XM_929986-LOC653441, with the master pluripotency master regulator SOX2 being separated to a different cluster. Six of these 12 have prior literature support for being involved in ES cell 
Table 3 Comparison of Triple-Link with MCL and Affinity Propagation

\begin{tabular}{llll}
\hline AGI & Cluster ID $(T L)$ & Cluster ID $(\mathrm{MCL})$ & Cluster ID (AP) \\
\hline AT5G58010 & 1 & 14 & 28 \\
\hline AT5G19790 & 1 & 14 & 28 \\
\hline AT1G27740 & 1 & 14 & 28 \\
\hline AT5G25810 & 1 & 14 & 118 \\
\hline AT1G66470 & 1 & 14 & 118 \\
\hline AT2G28160 & 1 & 14 & Size: Cluster 28: 5 TFs Cluster 118: 10 TFs \\
\hline Cluster size & 6 & 28 (Others not shown) & 140 \\
\hline AT2G36400 & 7 & 15 & 140 \\
\hline AT3G01330 & 7 & 15 & 140 \\
\hline AT3G50870 & 7 & 15 & 140 \\
\hline AT4G37740 & 7 & 15 & 143 \\
\hline AT1G34355 & 7 & 15 & 143 \\
\hline AT4G23800 & 7 & 15 & 143 \\
\hline AT5G25475 & 7 & 15 & 191 \\
\hline AT2G22840 & 7 & 15 & 191 \\
\hline AT5G24330 & 7 & 15 & Size: Cluster 140: 5 TFs Cluster 143: 8 TFs Cluster 191: 6 TFs \\
\hline Cluster size & 9 & 14 (Others not shown) & \\
\hline
\end{tabular}

maintenance. However, the lack of inclusion of SOX2 indicates that this cluster may be too restrictive as SOX2 is a well-known regulator of ES pluripotency. For the TF cluster controlling neural development, AP produced a cluster of eight TFs, two less than the one identified by Triple-Link (Table 2). These eight TFs are BC008687NEUROG1, NM_001965-EGR4, NM_002478-MYOD1, NM_002700-POU4F3, NM_006161-NEUROG1, NM_ 006732-FOSB, NM_152568-FLJ25169, NM_173849-GSC. AP also divided the Arabidopsis root growth clusters (shown in Table 2) into multiple clusters (Table 3). We examined eight genes in cluster 118, and found that four of them do not have firm literature support for a role in root growth. These four genes are AT1G10610, AZF1AT5G67450, WRKY35-AT2G34830, WRKY36-AT1G 69810, and WRKY19-AT1G68150. There are six genes in cluster 191, and three genes out of these six, APTX -AT5G01310, SUVH5-AT2G35160 and Wrinkled1AT3G54320, show evidence of being growth genes. Cluster 143 contains 8 genes and three of them, TUBBY 8 (AT1G16070), AT5G25475, and EBS(AT4G22140) are lacking literature support for being growth genes. These results suggest that AP tends to produce smaller subgraphs that do not have cohesive functions. All this evidence suggest that Triple-Link outperformed both MCL and $\mathrm{AP}$ in that it can produce more functionally interpretable TF clusters with a size ideal for either functional analysis or experimental validation.

In addition to proving the efficiency of TF-Cluster by comparing with other methods, we also examined the number of connectivities within the derived clusters and between each cluster and other genomic genes. Two examples were shown in Figure 1A and 1B. It is obvious that the connectivities between TFs within the cluster are much more than those between TFs within a cluster and other genomic genes, suggesting that TF-Cluster can generate clusters by breaking down connected TFs from the weakest links.

Although we have demonstrated that Triple-Link performed better than AP and MCL in generating optimal cluster size, we have tested it to only two data sets. For this reason, we suggest users to try Triple-Link together with AP and MCL with multiple parameter choices so that it can be tested with a variety of data sets from various experimental conditions and species. What is interesting is that after we developed and tested Triple-Link, we found it can produce a cluster size that is between those that can be generated by AP and MCL. In this sense, AP, Triple-Link, and MCL form an array of methods for decomposing SCCM matrix. Although we believe Triple-Link performs better in decomposing SCCM because it was specifically designed and tuned up for this purpose, firm conclusion can be drawn only upon extensive tests being completed.

\section{Spearman rank correlation is a better method than Pearson correlation for associating TFs that have loose coordination}

The success in identifying many TF clusters with functional coordination can be at least partially ascribed to the efficiency of the Triple-Link decomposition algorithm. To explore how the method used for measuring 


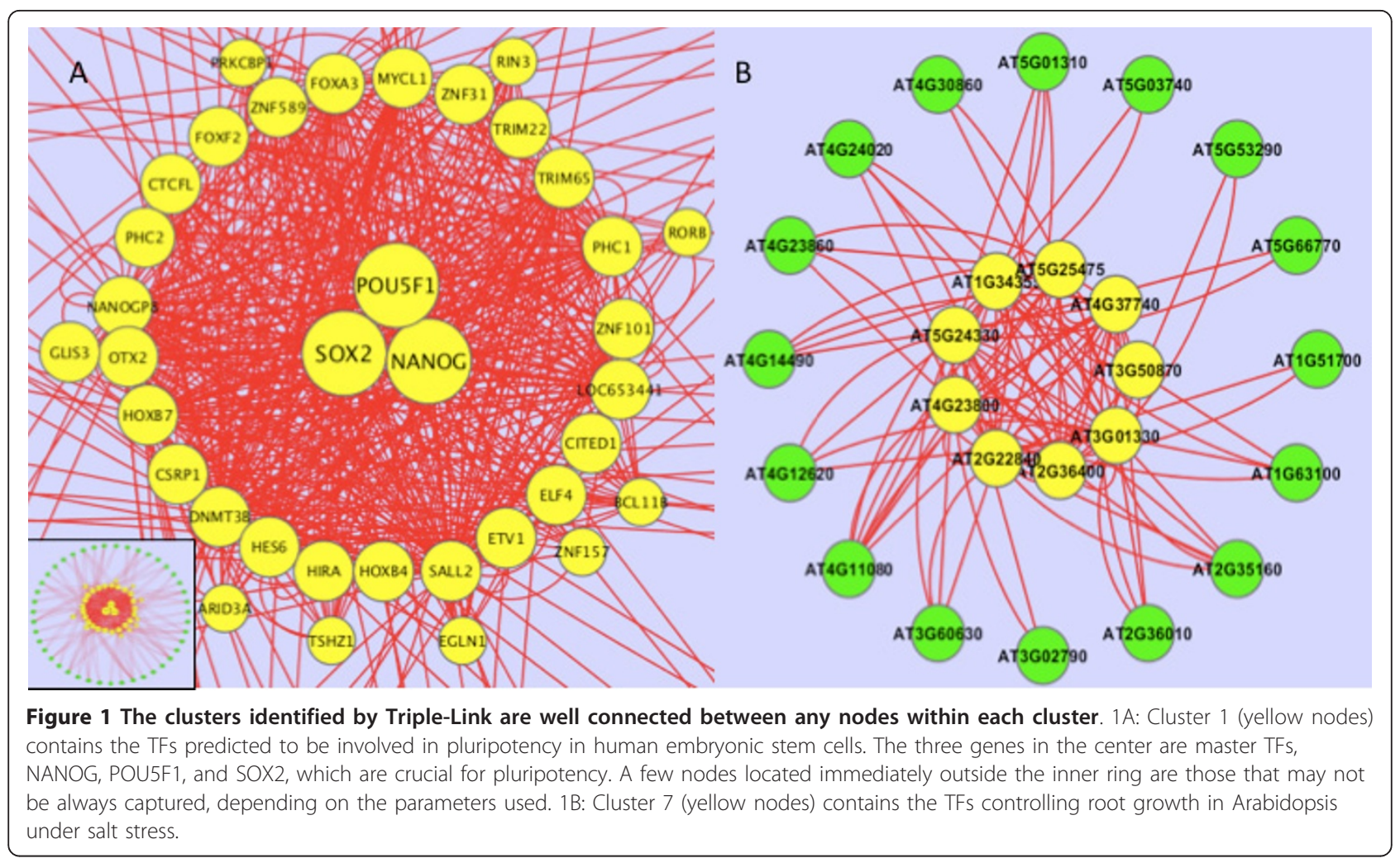

gene association can affect results, we compared Spearman rank correlation with Pearson product-moment, which is widely utilized in almost all coexpression analyses. Due to the noise arising from complicated interactions during transcription, we hypothesize that the Spearman rank correlation that emphasizes looser trend correlations may perform better in identifying functionally coordinated gene clusters, as shown in an early study[91]. To prove Spearman rank correlation is a better choice for the purpose of this study, we evaluated the coexpression analysis outcomes resulting from simple linear regression and Spearman and found that the Spearman's rank correlation indeed performs better than linear regression in finding clusters of biologically associated genes.

Spearman's rank correlation coefficient (called "rho") is a non-parametric (distribution-free) rank statistic [92], which is a measure of the strength of the association between two variables when the data are ordinal or do not follow a Gaussian distribution. It is a measure of a monotone association used when the distribution of the data makes Pearson's correlation coefficient undesirable or misleading. To test this, we performed the ShapiroWilk normality test and found that among 16,219 expressed genes, only 996 genes have a p value $>0.05$, suggesting that the expression of most individual genes do not strictly follow a Gaussian distribution, further suggesting that the use of non-parametric methods may be more appropriate.

To explain how the distribution of a gene influences its rank in the coexpressed gene lists when different association methods are employed, we used NM_004426-PHC1 as an example. We set PHC1 as a dependent variable and then examined the ranks of some other genes that have either a normal distribution or ones that depart from the normal distribution. This can be accomplished by a graphic method called Q-Q plot in which the quantiles of two variables are plotted again each other. These plots are displayed in Figure 2.

In Figure 2, we showed that SOX3 has an approximate normal distribution because the points in the normal Q-Q plot (top left) lie approximately in a straight line. In this case, SOX3 is the $47^{\text {th }}$ most coexpressed gene with PHC1 regardless of whether Spearman, Pearson, or regression is used. Q-Q plots shown in Figure 2 suggested that RGC32 and HAND2 deviate from the normal distribution. For these genes, we found that Spearman and regression/Pearson do make a difference. For the genes that deviate in a manner similar to RGC32 (where the observed highest quantiles are less than the highest theoretical quantiles), linear regression (LR, hereafter) gave a higher rank $\left(41^{\text {st }}\right)$ while Spearman gives a lower rank $\left(86^{\text {th }}\right)$ in the list of genes coexpressed with NM_004426 (PHC1). Several other genes including NM_002448-MSX1 (LR 42 ${ }^{\text {th }}$, 


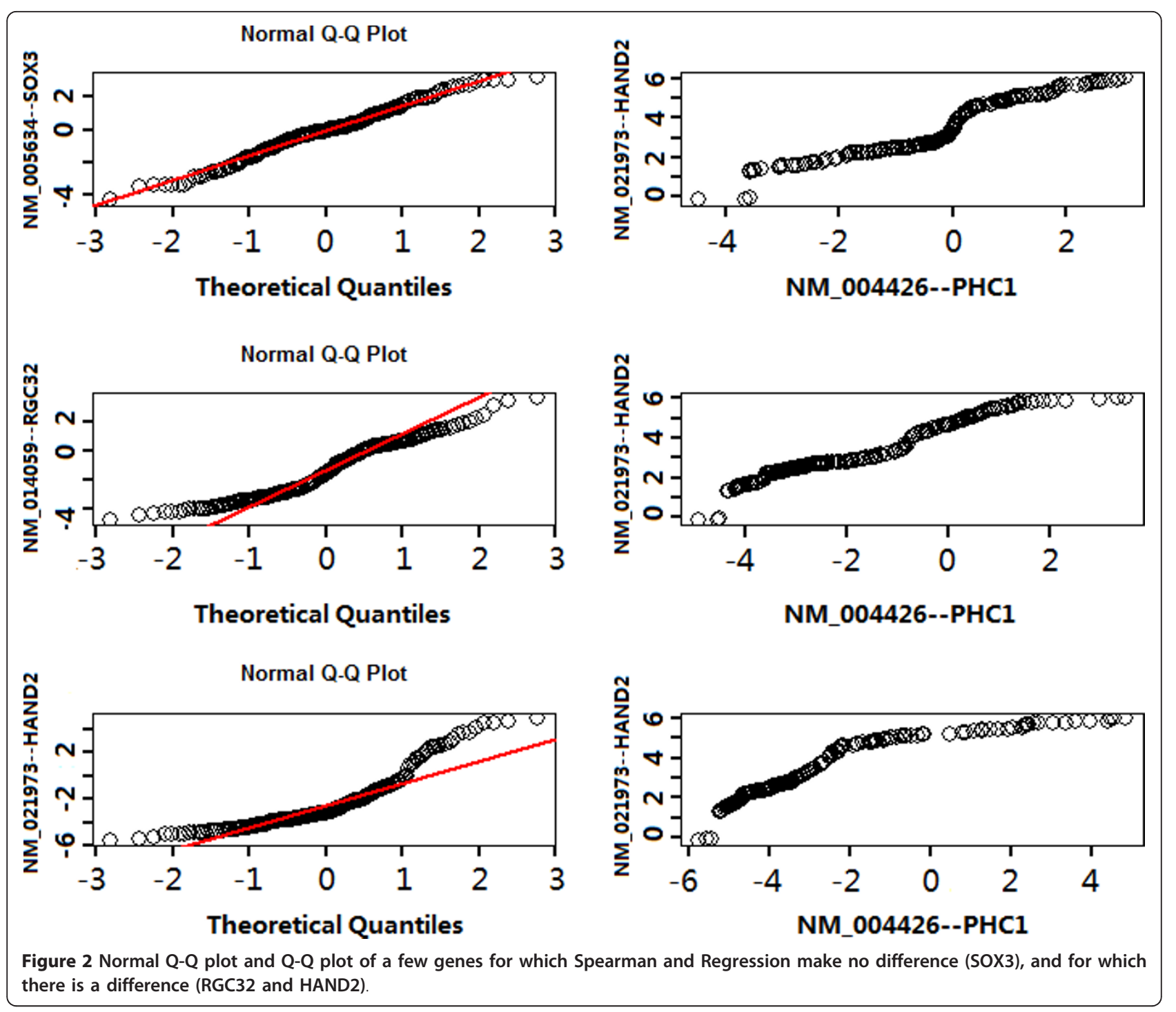

Spearman $\left.65^{\text {th }}\right)$, NM_005270-GLI2(LR 39 ${ }^{\text {th }}$, Spearman $\left.61^{\text {th }}\right)$, NM_007129-ZIC2 (LR 27 $7^{\text {th }}$, Spearman $\left.48^{\text {th }}\right)$, NM 012204-GTF3C4(LR $41^{\text {th }}$, Spearman $\left.86^{\text {th }}\right)$, NM_033132ZIC5(LR $33^{\text {th }}$ Spearman $60^{\text {th }}$ ) showed this type of deviation in that all have a higher rank when regression/ Pearson is used rather than Spearman. For the genes that deviate in a manner similar to HAND2 (where the observed highest quantiles are greater than the highest theoretical quantiles), Spearman gave a higher rank while linear regression/Pearson gave a lower rank $\left(75^{\text {th }}\right)$ in the coexpressed gene list with PHC1. Several other genes having this type of deviation include NM_005253-FOSL2 (LR $81^{\text {th }}$, Spearman 50th), NM_005257-GATA6 (LR 82 ${ }^{\text {th }}$, Spearman $56^{\text {th }}$ ), NM_005342-HMGB3(LR 91 ${ }^{\text {th }}$, Spearman $\left.69^{\text {th }}\right)$, NM_023033-METTL1(LR 95 ${ }^{\text {th }}$, Spearman 58), NM_002653-PITX1(LR $72^{\text {th }}$, Spearman $\left.31^{\text {th }}\right)$. We chose $\mathrm{PHC} 1$ as the dependent variable in regression because it does not have a normal distribution itself (Figure 2, top, right panel) and thus can represent most other genes that do not obey a normal distribution.

Having demonstrated that Spearman and Pearson indeed have some differences in identifying coordinated TFs, we now show that Spearman is capable of capturing more biologically meaningful relationships with gene expression data. We examined the overlap of the top 50 most tightly coexpressed genes between three master TFs regulators, NANOG, POU5F1, and SOX2. When Spearman correlation was employed, we obtained 35 coexpressed genes that were common in three gene lists, each containing the top 50 genes most coexpressed to NANOG, POU5F1 and SOX2 (Table 4). When regression/Pearson correlation was used, we obtained only 24 common genes. Of the 35 identified by Spearman correlation analysis, 22 are common to the 24 
Table 4 The intersection of coexpressed genes to NANOG, SOX2, and POU5F1 when Spearman and regression are used

\begin{tabular}{ll}
\hline Common Genes & Unique Genes \\
\hline BC069807-NANOGP8 & Regression/Pearson \\
BC090958-SALL2 & \\
BC099704-NANOGP8 & BC093979-HESX1[117] \\
NM_001421-ELF4 & NM_032805-ZNF206 (ZSCAN10) [23,24] \\
NM_003106-SOX2 & \\
NM_003325-HIRA & Spearman \\
NM_004078-CSRP1 & AF454056-PRKCBP1 [60] \\
NM_004426-PHC1 & BC010105-NASP \\
NM_004427-PHC2 & BC098403-ETV1 [28,29] \\
NM_004497-FOXA3 & CR627389-ETV1 [28,29] \\
NM_005375-MYB & NM_002653-PITX1 \\
NM_005634-SOX3 & NM_002701-POU5F1 [25] \\
NM_006892-DNMT3B & NM_005224-ARID3A \\
NM_016089-ZNF589 & NM_005239-ETS2 [118] \\
NM_018645-HES6 & NM_005407-SALL2 [25] \\
NM_021728-OTX2 & NM_006074-TRIM22 [32] \\
NM_022051-EGLN1 & NM_021958-HLX1 \\
NM_024504-PRDM14 & NM_021973-HAND2 \\
NM_024865-NANOG & NM_024015-HOXB4 [33] \\
NM_033204-ZNF101 & \\
NM_173547-TRIM65 & \\
XM_929986-LOC653441 & \\
\hline &
\end{tabular}

genes identified by regression, and 13 are unique to Spearman. Eight out of these 13 genes have literature support for being involved in hES cells. This suggests that Spearman correlation is capable of capturing a larger list of functionally associated TFs, possibly because of its ability to capture those with a looser coordination in expression.

\section{Discussion}

The SCCM is a more informative measure for TF coordination than simple coexpression

Existing coexpression analysis is typically either correlation- or regression-based. Due to the variation in the strength of coordination between TFs or TFs and other genes, mandatory implementation of any cut-off threshold in correlation or regression-based coexpression analyses often leads to the elimination of those TFs having relatively weak coordination strength with other genes. An example would be where TF $A$ is involved in stress response and another TF $B$ is a regulator controlling organ development. Due to the need for rapid response under stress conditions, TF $A$ may have 100 coexpressed genes with a correlation coefficient varying between $0.85 \sim 0.95$ while $B$ has 100 coexpressed genes with a correlation coefficient varying from $0.55 \sim 0.70$. Genome-wide coexpression analysis often disregards TF B due to its low coexpression strength with other genes. We argue that TFs with relatively lower coexpression strength may be intrinsic to the characteristics of some cellular activities or events and that this lower coexpression strength should not be used a priori to eliminate TFs. The SCCM was developed to deal with this issue so that TFs with lower association strength are not eliminated at an early stage. However, at the decomposition stage, any TF that does not share coexpressed genes with other TFs was automatically eliminated.

When the coordination between two TFs is measured by the number of coexpressed genes, the context of all genes genome-wide are taken into account (Figure 3). Therefore, every entry in SCCM reflects a more biologically meaningful measure as compared to the absolute distance represented by the correlation coefficient or regression $\mathrm{p}$ value.

\section{TF-Cluster identifies different TFs as compared to TF-}

finder

Interestingly, most TFs controlling root growth as identified by TF-Cluster are different from those identified by TF-finder [5]. For instance, TF-finder identified a B3 family TF (AT2G16210) and GRF7 while TF-Cluster identified GRF1, 2 and 3, and a different B3 family member (AT5G25475). This is not surprising because the two methods use different principles. TF-finder uses bait and guide genes aided by multiple correlation analysis to identify TFs while TF-Cluster uses relatively loose coordination analysis following by network decomposition. The TFs within each cluster identified by TF-Cluster are typically cohesive in function as shown in Table 1 and 2. Such a phenomenon was not observed in the outputs resulting from TF-finder [5]. Disparate functions

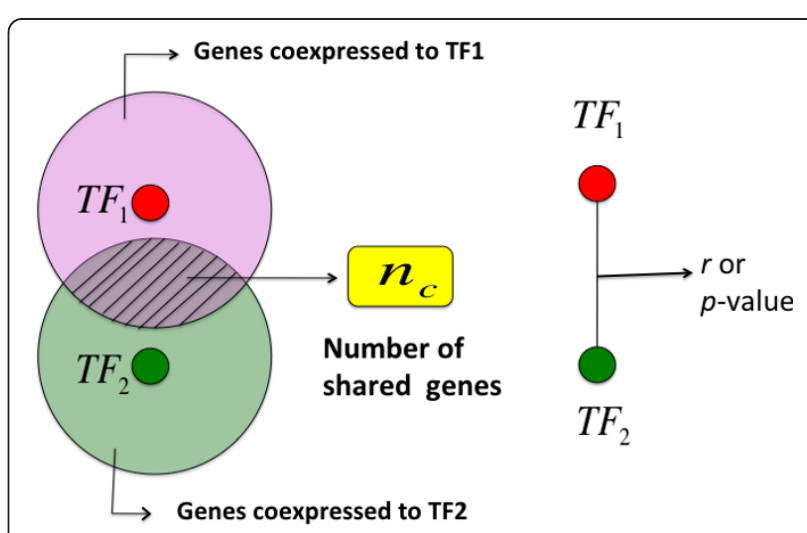

Figure 3 Shared coexpression connectivity represents the coordination of two TFs in the context of other genes while correlation coefficient/regression $p$ value between two TFs only reflects the distance between these two TFs with regard to coexpression 
of the genes shown in Table 1 and supplemental Tables in the TF-finder article [5] are obvious and such a feature is probably rooted in the use of bait and guide genes, which have distinct functions..

\section{Interpretation and validation of TF cluster function}

To identify the function of each derived cluster, the user may need to search the existing recent literature. This is because, in the existing database, most genes encoding TFs have very simple annotation. For example, an annotation may read as follows: molecular function: transcription activity; cellulose component: nucleus; biological process: regulation of transcription. This kind of annotation does not help in figuring out the function of a TF-Cluster. When applied to higher plants and mammals that have a variety of cell types and developmental stages, caution needs to be exercised in interpreting the functions of each TF in a cluster. It is also important to find the articles whose research was done using the same tissue types. A cluster of TFs recognized from TF-Cluster contains those that are loosely coordinated in expression. There is thus no guarantee that these TFs function in the same cells, or bind to the same set of target genes though it is highly likely that a subset of them may share a subset of target genes. For example, the roots are comprised of many cell types, and several TF clusters we identified apparently function in different locations. For instance, Cluster 2 contains TFs that function at the tip of roots (Table 2), and Cluster 5 contains TFs that function in vascular tissues (Table 2). Although TFs in the same cluster can be involved in remote events in different cell types in the same organ or even whole plants, depending on how the samples are harvested, the confirmation of subset TFs binding to a set of target genes is still helpful in consolidating the cluster. In this regard, the availability of CHIP-seq or CHIP-on-chip data from the specific cell types will aid cluster validation. Although this kind of data is still scarce at the time being, the DREAM project has started to collect data to facilitate this kind of validation (http://wiki.c2b2.columbia.edu/dream/index.php/ The_DREAM_Project). In addition, with the availability of third generation sequencing technology, this kind of data will soon become widely available. Currently, examination of co-existing cis-elements bound by the different TFs of the same cluster is helpful if the method is applied to data from bacteria and yeast. However, it is of little value if the method is applied to higher plants and mammals simply because we currently do not know to which motifs these TFs bind. Caution must be taken in using motif information to interpret the clusters because the mere presence of a motif does not indicate it is an active one. In this sense, CHIP-on-chip or CHIP-seq data are more valuable.
Although not absolutely required, a general understanding of the biological process of interest and also the data collected can help interpret the derived TF clusters. It is important to recognize the limitation of any particular data set and to avoid over-interpretation of the derived TF clusters. Generally speaking, the biological process of interest should be activated and dominant in the data collected. If one cannot identify a TFcluster for a specific biological process, try to get adjacent spatial or temporal data sets. This will become possible when we have ample gene expression data in a public domain.

\section{How many coexpressed genes should be used to measure coexpression between two TFs when SCCM is constructed?}

It is conceivable that the use of the top 50,100 , and 150 could not significantly affect true positive rate for each cluster. This is because these genes are used as a measurement, not as participants. To get an idea of which choice is optimal, we examined two median size clusters: human Cluster 1 and Arabidopsis Cluster 2 for cluster size and true positive discovery rate with respect to the different schemes of top genes, and obtained the following results:

For human Cluster 1, three schemes of top 50, 100 and 150 yielded three clusters of 22,24 and 31 TFs, respectively, with positive rates of $77.2 \%, 66 \%$, and $55 \%$. For Arabidopsis Cluster 2, three schemes of top 50, 100 and 150 yielded three clusters of 14,18 and $22 \mathrm{TFs}$, respectively, with positive rates of $71.4 \%, 72.2 \%$, and $63.6 \%$. These results indicate that the use of 50 is good but may have less prediction power for novel genes; that the top 150 could not only potentially increase the size of the cluster but also introduce false positives; and that the top 100 can achieve higher positive discovery rate than the top 150 while maintaining decent prediction power of novel TFs. Nevertheless, we suggest users compare the three schemes in real application because other factors like data size and genes involved in the biological process of interest can also affect the cluster size and accuracy.

\section{Conclusions}

TF-Cluster can be used to cluster all TFs into multiple clusters of various sizes using gene expression data from a biological process. Each cluster contains the TFs assumed to function coordinately in time to regulate the multiple facets of a biological process. The TF-Cluster algorithm outputs the TF clusters according to the order of association. Clusters of closely associated TFs in the coexpression networks will be displayed earlier. Compared to TF-finder, TF-Cluster can identify many groups of TFs, each with a cohesive function. TF- 
Cluster does not require an existing knowledgebase, and thus can be used more widely if only the microarray data representing many "snapshots" of a biological process are available. With the increased availability of gene expression data in public resources, TF-Cluster will no doubt have a wide variety of applications in the future. Nevertheless, TF-Cluster may not be useful when a compendium data set contains no more than 30 samples/chips. This assumption is based on the fact that we have tried TF-finder to a data set containing 36 chips from Poplar, and we could identify TF clusters that can be explained biologically. In addition, TF-Cluster may not be applicable to some biological processes in which few TFs are involved and function with little overlapping in time. Finally, since the whole method is coexpressionbased, the TF-Cluster pipeline can be potentially used for pathway analysis. It certainly can be used to identify coordinated or cross-talking pathways or predict new pathway genes. The pipeline was applied in Practical Extraction and Report Language (PERL), and parallel techniques were applied to accelerate the analysis (see Methods). For analyzing a data set comprised of human chips, and a coexpression network of 2,180 human TFs, it takes 2-4 hours in our Linux server. Interested users can send a request to Hairong Wei (hairong@mtu.edu).

\section{Methods}

\section{Microarray Data and Data Preprocessing Human microarray data set}

One data set contains 104 high-density human gene expression arrays, each with 388,634 probes from 36,494 human locus identifiers from the HG17 assembly. These 104 chips were from 15 experiments in which stem cells were treated with different reagents that disrupted pluripotency while triggering differentiation; the reagents and the conditions included: TPA (a phorbyl ester) treatment in conditioned medium, TPA treatment in TeSR medium, BMP4 treatment with FGF, BMP4 treatment without FGF, and co-culture with mouse OP9 cells. The other dataset contains 85 high-density human gene expression arrays, each with 381,002 probes from 47,633 human locus identifiers from the HG18 assembly. This dataset was collected from a set of experiments where a variety of different growth factors were applied to human ES cells at varying conditions for 3 days. Both platforms were manufactured by NimbleGen Systems (http://www. nimblegen.com). All probes are 60 mers and all chips were hybridized to Cy5 labeled mRNAs extracted from human embryonic stem cells (hESCs) from undifferentiated to differentiated stages. Raw data were extracted using NimbleScan software v2.1. The two data sets were joined by gene mapping via selection of shared common probes between the same gene on the two platforms. More than $99.5 \%$ of mapped genes share more than 6 probes, and the signal intensities from these common probes were normalized with the Robust Multiple-chip Analysis (RMA) algorithm [93]. The whole dataset obtained contains 36,398 genes, which was used to construct coexpression matrix SCCM. Here we state that the stem cell research reported in this paper was approved under protocol SC02008-0002 of the Stem Cell Research Oversight (SCRO) Committee.

\section{Arabidopsis microarray data set}

Microarray data sets were downloaded from multiple resources. The salt stress experimental data set contains 108 chips from 6 experiments (GSE7636, 7639, $7641,7642,8787,5623)$ and was downloaded from the NCBI GEO website: http://www.ncbi.nlm.nih.gov/geo/. All data mentioned above are derived from hybridization of Affymetrix 25 k ATH1 microarrays [94]. The original CEL files were processed by the robust multiarray analysis (RMA)[93] algorithm using the Bioconductor package. For quality control we used methods that were previously described [95]. This data set was recently used for identifying TFs involved in salt stress response and growth [5].

Building shared coexpression connectivity matrix (SCCM) Let $T=\left\{y_{1}, y_{2}, \ldots, y_{p}\right\}$ denote the set of TFs known in a genome, and $y_{i}(i=1, \ldots, p, m \geq \psi)=\left\{e_{i 1}, e_{i 2}, e_{i 3}, \ldots, e_{i m}\right\}$ is the gene expression profile of the $i^{t h}$ TF in $m^{\text {th }}$ microarray chip. Also let $G=\left\{x_{1}, x_{2}, \ldots, x_{q}\right\}$ represent all genes in the genome, and $x_{q}(i=1, \ldots, n, m \geq \psi)=\left\{e_{q 1}, e_{q 2}, e_{q 3}, \ldots\right.$, $\left.e_{q m}\right\}$ is the gene expression profile of the $q^{\text {th }}$ gene in $m^{\text {th }}$ microarray chip. For this analysis, $\psi$ is the minimally required number of chips that should be used for this kind of analyses (our empirical $\psi \geq 50$ ). For each pair of $y_{i}$ and $x_{q}(i=1, \ldots p ; q=1, \ldots, n)$, a Spearman rank correlation rho $\rho_{i q}=1-6 \sum_{c=1}^{m}\left(r_{e_{q c}}-r_{e_{i c}}\right)^{2} / m\left(m^{2}-1\right)$ or a regression $\mathrm{p}$ value is calculated (Persson et al., 2005; Wei et al., 2006). Where $r_{e_{q c}}$ and $r_{e_{i c}}$ are the ranks of TF $i$ and TF $q$. Then for each $y_{i}$, we rank all the genes in $G$ by $\rho_{i q}$ and retain the top $\Omega$ ( $\Omega$ can be 50,100 , or 150$)$ genes that are co-expressed most closely with $y_{i}$, then denote this set of genes as $G_{i}$.

After the above co-expression analysis, we are now able to build a $p \times p$ symmetric matrix $A$, whose both row and column variables are the TFs in $T$ (Figure 4 ), and each entry $a_{i j}(i, j=1, \ldots, p)$ represents the number of shared most co-expressed genes between TFs $y_{i}$ and $y_{j}$, that is the number of common genes between $G_{i}$ and $G_{j}$, namely $a_{i j}=G_{i} \cap G_{j}$, Hereafter, we defined $a_{i j}$ as the number of connectivity $\left(n_{c}\right)$ for the pair of TFs.

\section{Decomposition of SCCM transcription factor network}

Given matrix A and a set of TFs, $T=\left\{y_{1}, y_{2}, y_{3}, \ldots, y_{p}\right\}$, we can now decompose SCCM for the clusters of TFs. The 


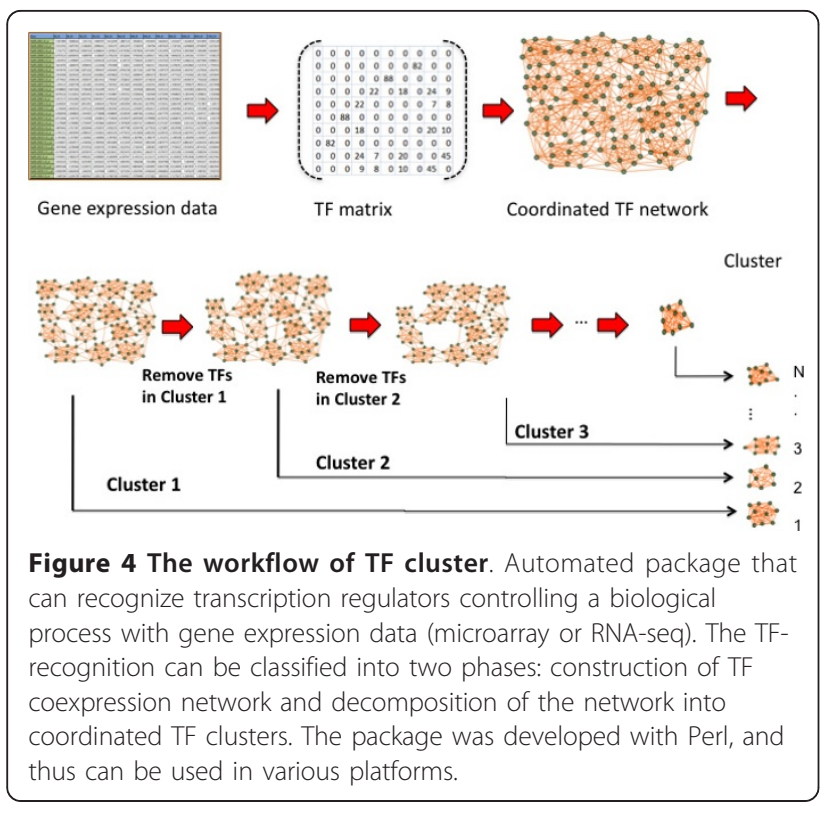

TFs in each cluster are assumed to work together to achieve some kind of functionality in a biological process. To achieve this, we developed a heuristic algorithm, Triple-Link, which always uses the two TFs with the maximal $n_{c}$ as a primer, and gradually adds other TFs that have significant connectivity with TFs that are already in the primer or primer-derived cluster. A significant connectivity is defined as the one with a value larger than a threshold of $n_{c}>\mu+\theta \delta$, where $\mu$ and $\delta$ are the mean and the standard deviation of non-zero connectivities contained in SCCM respectively. We have three $\theta_{1}, \theta_{2}, \theta_{3}$ that are corresponding to three thresholds that were used to determine if another candidates should be joined, with $\theta_{1}$, to be the most and $\theta_{3}$ to be the least stringent one. Our empirical values of three theta are located within the following ranges: $\theta=\left(\left\{\theta_{1}, \theta_{2}, \theta_{3}\right\} \subset(\{2.5 \sim 1.5,2.0 \sim 1.0,1.5 \sim 0.5\})\right.$, where $\theta_{1}>\theta_{2}>\theta_{3}$ is required for implementation of different stringency. Since each cluster started with two TFs, the third TF was added in on the condition that it had only two significant connectivities with the existing two TFs. After this, we required a candidate TF to have only three significant connectivities with any TFs that were already in the cluster grown from the primer regardless of the size of existing cluster. Once a candidate TF was included in the cluster, it was then removed from $\mathrm{T}$. This process was then repeatedly executed until there were no more candidate TFs that shared at least three significant connectivities with the TFs within the cluster. All TFs in the cluster were removed from. $T=\left\{y_{1}, y_{2}, y_{3}, \ldots, y_{p}\right\}$. This process was then repeatedly executed until all TFs in $T=$ $\left\{y_{1}, y_{2}, y_{3}, \ldots, y_{p}\right\}$ with significant connectivity were removed. The detail procedure of this algorithm is described below:

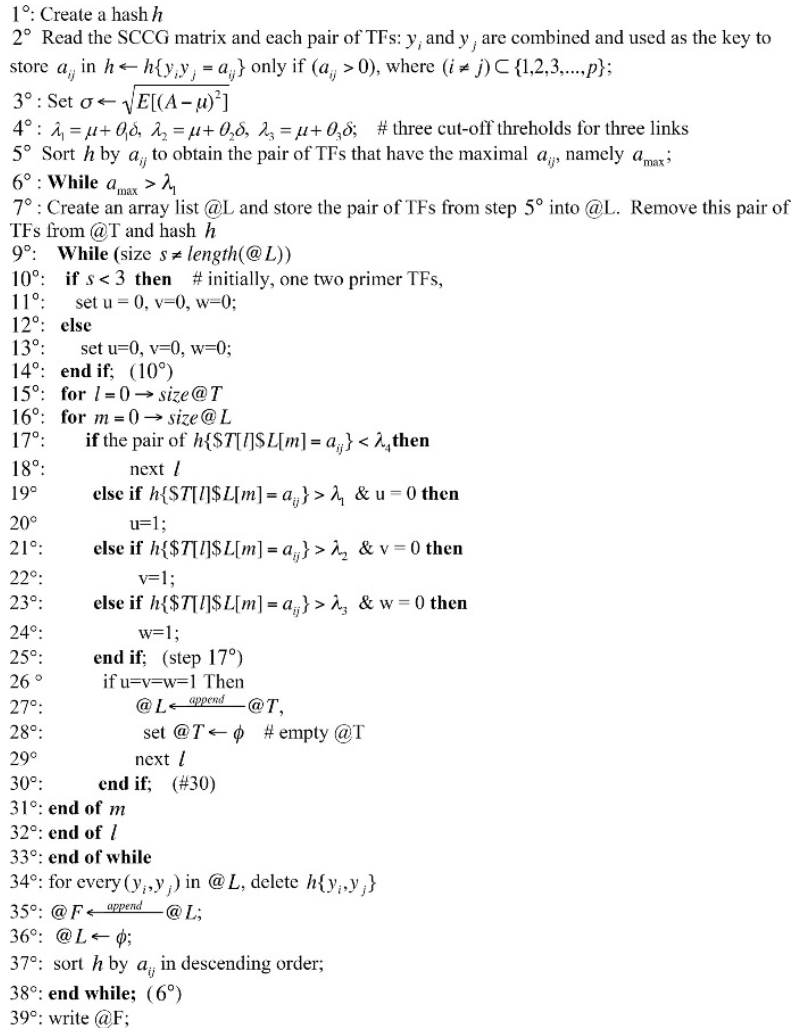

A workflow for TF pipeline is shown in Figure 4.

\section{Acceleration of TF-Cluster pipeline by enhancing CPU usage and eliminating non-essential steps}

Genome-wide coexpression analysis of all TFs, building SCCM, and decomposition of SCCM are all computationally intensive. To reduce computing time, we implemented multiple techniques to shorten the running time. The measures we took included: (1) Using Perl rather than R. Correlation matrix building is one of the most time consuming steps of this pipeline. For example, we needed to perform 2180(TFs) $\times 16219$ (genes) = $35,357,420$ correlation analyses with the human data of 189-dimentional samples, which took 10 days to run in $R$. When we switched to Perl, we could complete abovementioned correlation analyses in 1-2 hours; (2) Introducing parallel computing. Almost all computational servers now have multi-core processors that allow for parallel computing. To take advantage of this, we parallelized all non-sequential parts of the code, which increased the speed by a factor of at least 3 on our server. (3). Using a better algorithm. The loop is the most expensive operation in any computing language. We removed several loops by index point checking. (4) Reducing unnecessary Input/Output (IO). IO can significantly impact computational speed. Just the correlation matrix file alone produced in this study exceeds $3 \mathrm{~GB}$. To avoid unnecessary IO, we processed a single TF 
against all other genes' correlation on the fly, and only the top correlated gene list was output. This step reduced the memory usage by factor of 1000. (5) Avoid functions and modules if possible. Every function and module consumes over $1 \mathrm{~kb}$ for its mere existence. Function and module loading as well as argument passing take a lot of computational resources. We optimized code into only two concise scripts by replacing a lot of modules with only few lines of code, which made the program not only more efficient but also portable. For analyzing a data set comprising of human chips, and a coexpression network of 2180 human TFs, it took 2-4 hours in our Linux server (Dell PowerEdge Server 2990 III with Intel Xeon X5640 quadcore processor (3.16ghz), and 48 GB RAM).

\section{Availability and requirements}

The TF-Cluster pipeline was written in Perl. We will release the executable files free to academic, but may charge license fee for any commercial uses. Original source codes of the software can be made available under a suitable open-source agreement. For details, please contact: hairong@mtu.edu.

\section{Acknowledgements}

This project was partly supported with the start-up fund to Dr. Wei from the School of Forest Resources and Environment Science, Michigan Technological University. We thank Krista Eastman for editorial assistance. The authors declare competing financial interests: J.A.T. is a founder, stockowner, consultant and board member of Cellular Dynamics International (CDI). He also serves as scientific advisor to and has financial interests in Tactics II Stem Cell Ventures.

\section{Author details \\ ${ }^{1}$ Morgridge Institute for Research, 330 N. Orchard St., Madison, WI 53715, USA. ${ }^{2}$ Department of Biostatistics and Medical Informatics, University of Wisconsin, 600 Highland Ave., Madison, WI 53792, USA. ${ }^{3}$ Department of Cell \& Regenerative Biology, University of Wisconsin, 1300 University Ave., Madison, WI 53705, USA. ${ }^{4}$ School of Forest Resources and Environmental Science, Michigan Technological University, 1400 Townsend Drive, Houghton, MI 49931, USA. ${ }^{5}$ Department of Mathematics, Michigan Technological University, 1400 Townsend Drive, Houghton, MI 49931, USA. ${ }^{6}$ Department of Computer Science, Michigan Technological University, 1400 Townsend Drive, Houghton, MI 49931, USA. ${ }^{7}$ Program of Computing Science and Engineering, Michigan Technological University, 1400 Townsend Drive, Houghton, MI 49931, USA. ${ }^{8}$ Biotechnology Research Center, Michigan Technological University, 1400 Townsend Drive, Houghton, MI 49931, USA. ${ }^{9}$ Department of Molecular, Cellular, \& Developmental Biology, University of California Santa Barbara, Santa Barbara, CA, 93106, USA.}

\section{Authors' contributions}

JN developed the Perl code for building the SCCM matrix, merged the pipeline, and tuned-up the running time. RS was involved in project design, analysis of clusters, and writing part of the manuscript. $\mathrm{HZ}$ was involved in network plots, and code testing, FR ran $\mathrm{AP}$ and $\mathrm{MCL}, \mathrm{XC}$, contributed to the method. JT contributed human microarray data set and involved in manuscript edition. HW merged and preprocessed human data from different platforms, developed the overall frame of this project, Triple-Link algorithm and Perl code for Triple-Link, and wrote the majority of manuscript. All authors read and approved the final manuscript.

\section{References}

1. Takahashi K, Tanabe K, Ohnuki M, Narita M, Ichisaka T, Tomoda K, Yamanaka S: Induction of pluripotent stem cells from adult human fibroblasts by defined factors. Cell 2007, 131(5):861-872.

2. Yu J, Vodyanik MA, Smuga-Otto K, Antosiewicz-Bourget J, Frane JL, Tian S, Nie J, Jonsdottir GA, Ruotti V, Stewart $R$, et al: Induced pluripotent stem cell lines derived from human somatic cells. Science 2007, 318(5858):1917-1920.

3. Zhou Q, Brown J, Kanarek A, Rajagopal J, Melton DA: In vivo reprogramming of adult pancreatic exocrine cells to beta-cells. Nature 2008, 455(7213):627-632.

4. Mittler R, Blumwald E: Genetic engineering for modern agriculture: challenges and perspectives. Annu Rev Plant Biol 2010, 61:443-462.

5. Cui X, Wang T, Chen HS, Busov V, Wei H: TF-finder: a software package for identifying transcription factors involved in biological processes using microarray data and existing knowledge base. BMC Bioinformatics 2010, 11:425.

6. Faith JJ, Hayete B, Thaden JT, Mogno I, Wierzbowski J, Cottarel G, Kasif S, Collins JJ, Gardner TS: Large-scale mapping and validation of Escherichia coli transcriptional regulation from a compendium of expression profiles. PLOS Biol 2007, 5(1):e8.

7. Gardner TS, di Bernardo D, Lorenz D, Collins JJ: Inferring genetic networks and identifying compound mode of action via expression profiling. Science 2003, 301(5629):102-105.

8. Margolin AA, Nemenman I, Basso K, Wiggins C, Stolovitzky G, Dalla Favera R, Califano A: ARACNE: an algorithm for the reconstruction of gene regulatory networks in a mammalian cellular context. $B M C$ Bioinformatics 2006, 7(Suppl 1):S7.

9. Margolin AA, Califano A: Theory and limitations of genetic network inference from microarray data. Ann N Y Acad Sci 2007, 1115:51-72.

10. Qian J, Lin J, Luscombe NM, Yu H, Gerstein M: Prediction of regulatory networks: genome-wide identification of transcription factor targets from gene expression data. Bioinformatics 2003, 19(15):1917-1926.

11. Wei $H$, Kaznessis $Y$ : Inferring gene regulatory relationships by combining target-target pattern recognition and regulator-specific motif examination. Biotechnol Bioeng 2005, 89(1):53-77.

12. Kaern M, Elston TC, Blake WJ, Collins JJ: Stochasticity in gene expression: from theories to phenotypes. Nat Rev Genet 2005, 6(6):451-464.

13. Rowicka M, Kudlicki A, Tu BP, Otwinowski Z: High-resolution timing of cell cycle-regulated gene expression. Proc Natl Acad Sci USA 2007, 104(43):16892-16897.

14. Aulehla A, Pourquie O: Oscillating signaling pathways during embryonic development. Curr Opin Cell Biol 2008, 20(6):632-637.

15. Komili $\mathrm{S}$, Silver PA: Coupling and coordination in gene expression processes: a systems biology view. Nat Rev Genet 2008, 9(1):38-48.

16. Raser JM, O'Shea EK: Noise in gene expression: origins, consequences, and control. Science 2005, 309(5743):2010-2013.

17. Jiang C, Pugh BF: Nucleosome positioning and gene regulation: advances through genomics. Nat Rev Genet 2009, 10(3):161-172.

18. Becskei A, Kaufmann BB, van Oudenaarden A: Contributions of low molecule number and chromosomal positioning to stochastic gene expression. Nat Genet 2005, 37(9):937-944.

19. Raj A, Peskin CS, Tranchina D, Vargas DY, Tyagi S: Stochastic mRNA synthesis in mammalian cells. PLoS Biol 2006, 4(10):e309.

20. Enright AJ, Van Dongen S, Ouzounis CA: An efficient algorithm for largescale detection of protein families. Nucleic Acids Res 2002, 30(7):1575-1584.

21. Frey BJ, Dueck D: Clustering by passing messages between data points. Science 2007, 315(5814):972-976.

22. Giuliano CJ, Kerley-Hamilton JS, Bee T, Freemantle SJ, Manickaratnam R, Dmitrovsky E, Spinella MJ: Retinoic acid represses a cassette of candidate pluripotency chromosome $12 p$ genes during induced loss of human embryonal carcinoma tumorigenicity. Biochim Biophys Acta 2005, 1731(1):48-56

23. Wang ZX, Kueh JL, Teh CH, Rossbach M, Lim L, Li P, Wong KY, Lufkin T, Robson P, Stanton LW: Zfp206 is a transcription factor that controls pluripotency of embryonic stem cells. Stem Cells 2007, 25(9):2173-2182.

24. Yu HB, Kunarso G, Hong FH, Stanton LW: Zfp206, Oct4, and Sox2 are integrated components of a transcriptional regulatory network in embryonic stem cells. J Biol Chem 2009, 284(45):31327-31335. 
25. Giorgetti A, Montserrat N, Aasen T, Gonzalez F, Rodriguez-Piza I, Vassena R, Raya A, Boue S, Barrero MJ, Corbella BA, et al: Generation of induced pluripotent stem cells from human cord blood using OCT4 and SOX2. Cell Stem Cell 2009, 5(4):353-357.

26. Gopalakrishnan S, Van Emburgh BO, Shan J, Su Z, Fields CR, Vieweg J, Hamazaki T, Schwartz PH, Terada N, Robertson KD: A novel DNMT3B splice variant expressed in tumor and pluripotent cells modulates genomic DNA methylation patterns and displays altered DNA binding. Mol Cancer Res 2009, 7(10):1622-1634.

27. Meshorer E, Yellajoshula D, George E, Scambler PJ, Brown DT, Misteli T: Hyperdynamic plasticity of chromatin proteins in pluripotent embryonic stem cells. Dev Cell 2006, 10(1):105-116.

28. Loh YH, Wu Q, Chew JL, Vega VB, Zhang W, Chen X, Bourque G, George J, Leong B, Liu J, et al: The Oct4 and Nanog transcription network regulates pluripotency in mouse embryonic stem cells. Nat Genet 2006, 38(4):431-440.

29. Fouse SD, Shen Y, Pellegrini M, Cole S, Meissner A, Van Neste L, Jaenisch R, Fan G: Promoter CpG methylation contributes to ES cell gene regulation in parallel with Oct4/Nanog, PcG complex, and histone H3 K4/K27 trimethylation. Cell Stem Cell 2008, 2(2):160-169.

30. Kranc KR, Bamforth SD, Braganca J, Norbury C, van Lohuizen M, Bhattacharya S: Transcriptional coactivator Cited2 induces Bmi1 and Mel18 and controls fibroblast proliferation via Ink4a/ARF. Mol Cell Biol 2003, 23(21):7658-7666.

31. Kranc KR, Schepers $H$, Rodrigues NP, Bamforth S, Villadsen E, Ferry $H$, Bouriez-Jones T, Sigvardsson M, Bhattacharya S, Jacobsen SE, et al: Cited2 is an essential regulator of adult hematopoietic stem cells. Cell Stem Cell 2009, 5(6):659-665.

32. Greber B, Lehrach $H$, Adjaye J: Silencing of core transcription factors in human EC cells highlights the importance of autocrine FGF signaling for self-renewal. BMC Dev Biol 2007, 7:46

33. Stein Ml, Zhu J, Emerson SG: Molecular pathways regulating the selfrenewal of hematopoietic stem cells. Exp Hematol 2004, 32(12):1129-1136.

34. Miyake N, Brun AC, Magnusson M, Miyake K, Scadden DT, Karlsson S: HOXB4-induced self-renewal of hematopoietic stem cells is significantly enhanced by p21 deficiency. Stem Cells 2006, 24(3):653-661.

35. Kelz MB, Nestler EJ: deltaFosB: a molecular switch underlying long-term neural plasticity. Curr Opin Neurol 2000, 13(6):715-720.

36. Joosten PH, van Zoelen EJ, Murre C: Pax1/E2a double-mutant mice develop non-lethal neural tube defects that resemble human malformations. Transgenic Res 2005, 14(6):983-987.

37. Vahava O, Morell R, Lynch ED, Weiss S, Kagan ME, Ahituv N, Morrow JE, Lee MK, Skvorak AB, Morton CC, et al: Mutation in transcription factor POU4F3 associated with inherited progressive hearing loss in humans. Science 1998, 279(5358):1950-1954.

38. Bosnakovski D, Daughters RS, Xu Z, Slack JM, Kyba M: Biphasic myopathic phenotype of mouse DUX, an ORF within conserved FSHD-related repeats. PLoS One 2009, 4(9):e7003.

39. Garcia-Barcelo MM, Lau DK, Ngan ES, Leon TY, Liu TT, So MT, Miao XP Lui VC, Wong KK, Ganster RW, et al: Evaluation of the thyroid transcription factor-1 gene (TITF1) as a Hirschsprung's disease locus. Ann Hum Genet 2007, 71(Pt 6):746-754.

40. Bajard L, Relaix F, Lagha M, Rocancourt D, Daubas P, Buckingham ME: A novel genetic hierarchy functions during hypaxial myogenesis: Pax3 directly activates Myf5 in muscle progenitor cells in the limb. Genes Dev 2006, 20(17):2450-2464.

41. Teboul L, Hadchouel J, Daubas P, Summerbell D, Buckingham M, Rigby PW: The early epaxial enhancer is essential for the initial expression of the skeletal muscle determination gene Myf5 but not for subsequent, multiple phases of somitic myogenesis. Development 2002, 129(19):4571-4580.

42. Hadchouel J, Tajbakhsh S, Primig M, Chang TH, Daubas P, Rocancourt D, Buckingham M: Modular long-range regulation of Myf5 reveals unexpected heterogeneity between skeletal muscles in the mouse embryo. Development 2000, 127(20):4455-4467.

43. Daubas P, Crist CG, Bajard L, Relaix F, Pecnard E, Rocancourt D, Buckingham M: The regulatory mechanisms that underlie inappropriate transcription of the myogenic determination gene Myf5 in the central nervous system. Dev Biol 2009, 327(1):71-82.
44. Daubas P, Tajbakhsh S, Hadchouel J, Primig M, Buckingham M: Myf5 is a novel early axonal marker in the mouse brain and is subjected to posttranscriptional regulation in neurons. Development 2000, 127(2):319-331.

45. Home P, Ray S, Dutta D, Bronshteyn I, Larson M, Paul S: GATA3 is selectively expressed in the trophectoderm of peri-implantation embryo and directly regulates Cdx2 gene expression. J Biol Chem 2009, 284(42):28729-28737

46. $\mathrm{Xu} \mathrm{RH:} \mathrm{In} \mathrm{vitro} \mathrm{induction} \mathrm{of} \mathrm{trophoblast} \mathrm{from} \mathrm{human} \mathrm{embryonic} \mathrm{stem}$ cells. Methods Mol Med 2006, 121:189-202.

47. Ma GT, Roth ME, Groskopf JC, Tsai FY, Orkin SH, Grosveld F, Engel JD, Linzer DI: GATA-2 and GATA-3 regulate trophoblast-specific gene expression in vivo. Development 1997, 124(4):907-914.

48. Buttitta L, Mo R, Hui CC, Fan CM: Interplays of Gli2 and Gli3 and their requirement in mediating Shh-dependent sclerotome induction. Development 2003, 130(25):6233-6243.

49. Cai CL, Liang X, Shi Y, Chu PH, Pfaff SL, Chen J, Evans S: IsI1 identifies a cardiac progenitor population that proliferates prior to differentiation and contributes a majority of cells to the heart. Dev Cell 2003, 5(6):877-889.

50. Brunelli S, Cossu G: A role for MSX2 and necdin in smooth muscle differentiation of mesoangioblasts and other mesoderm progenitor cells. Trends Cardiovasc Med 2005, 15(3):96-100.

51. Godwin AR, Capecchi MR: Hair defects in Hoxc13 mutant mice. J Investig Dermatol Symp Proc 1999, 4(3):244-247.

52. Futaki S, Hayashi Y, Emoto T, Weber CN, Sekiguchi K: Sox7 plays crucial roles in parietal endoderm differentiation in $\mathrm{F} 9$ embryonal carcinoma cells through regulating Gata-4 and Gata-6 expression. Mol Cell Biol 2004, 24(23):10492-10503.

53. Sturgeon K, Kaneko T, Biemann M, Gauthier A, Chawengsaksophak K, Cordes SP: Cdx1 refines positional identity of the vertebrate hindbrain by directly repressing Mafb expression. Development 138(1):65-74.

54. Filippi A, Tiso N, Deflorian G, Zecchin E, Bortolussi M, Argenton F: The basic helix-loop-helix olig3 establishes the neural plate boundary of the trunk and is necessary for development of the dorsal spinal cord. Proc Natl Acad Sci USA 2005, 102(12):4377-4382.

55. Onishi A, Peng GH, Hsu C, Alexis U, Chen S, Blackshaw S: Pias3-dependent SUMOylation directs rod photoreceptor development. Neuron 2009, 61(2):234-246.

56. Lee J, Sayegh J, Daniel J, Clarke S, Bedford MT: PRMT8, a new membranebound tissue-specific member of the protein arginine methyltransferase family. J Biol Chem 2005, 280(38):32890-32896.

57. Stegmann K, Boecker J, Kosan C, Ermert A, Kunz J, Koch MC: Human transcription factor SLUG: mutation analysis in patients with neural tube defects and identification of a missense mutation (D119E) in the Slug subfamily-defining region. Mutat Res 1999, 406(2-4):63-69.

58. Karas B, Amyot L, Johansen C, Sato S, Tabata S, Kawaguchi M, Szczyglowski K: Conservation of lotus and Arabidopsis basic helix-loophelix proteins reveals new players in root hair development. Plant Physiol 2009, 151(3):1175-1185.

59. Yi K, Menand B, Bell E, Dolan L: A basic helix-loop-helix transcription factor controls cell growth and size in root hairs. Nat Genet 2010, 42(3):264-267.

60. Menand B, Yi K, Jouannic S, Hoffmann L, Ryan E, Linstead P, Schaefer DG, Dolan L: An ancient mechanism controls the development of cells with a rooting function in land plants. Science 2007, 316(5830):1477-1480.

61. Singh SK, Fischer U, Singh M, Grebe M, Marchant A: Insight into the early steps of root hair formation revealed by the procuste1 cellulose synthase mutant of Arabidopsis thaliana. BMC Plant Biol 2008, 8:57.

62. Jung J, Won SY, Suh SC, Kim H, Wing R, Jeong Y, Hwang I, Kim M: The barley ERF-type transcription factor HvRAF confers enhanced pathogen resistance and salt tolerance in Arabidopsis. Planta 2007, 225(3):575-588

63. Wilson K, Long D, Swinburne J, Coupland G: A Dissociation insertion causes a semidominant mutation that increases expression of TINY, an Arabidopsis gene related to APETALA2. Plant Cell 1996, 8(4):659-671.

64. Jakoby M, Wang HY, Reidt W, Weisshaar B, Bauer P: FRU (BHLH029) is required for induction of iron mobilization genes in Arabidopsis thaliana. FEBS Lett 2004, 577(3):528-534.

65. Yuan YX, Zhang J, Wang DW, Ling HQ: AtbHLH29 of Arabidopsis thaliana is a functional ortholog of tomato FER involved in controlling iron acquisition in strategy I plants. Cell Res 2005, 15(8):613-621. 
66. Bennett $T$, van den Toorn A, Sanchez-Perez GF, Campilho A, Willemsen $V$, Snel B, Scheres B: SOMBRERO, BEARSKIN1, and BEARSKIN2 regulate root cap maturation in Arabidopsis. Plant Cell 2010, 22(3):640-654.

67. Willemsen V, Bauch M, Bennett T, Campilho A, Wolkenfelt $H, X u$ J, Haseloff J, Scheres B: The NAC domain transcription factors FEZ and SOMBRERO control the orientation of cell division plane in Arabidopsis root stem cells. Dev Cell 2008, 15(6):913-922.

68. Schlereth A, Moller B, Liu W, Kientz M, Flipse J, Rademacher EH, Schmid M, Jurgens G, Weijers D: MONOPTEROS controls embryonic root initiation by regulating a mobile transcription factor. Nature 2010, 464(7290):913-916.

69. Zhou W, Wei L, Xu J, Zhai Q, Jiang H, Chen R, Chen Q, Sun J, Chu J, Zhu L, et al: Arabidopsis Tyrosylprotein sulfotransferase acts in the auxin/ PLETHORA pathway in regulating postembryonic maintenance of the root stem cell niche. Plant Cell 2010, 22(11):3692-3709.

70. Li C, Potuschak T, Colon-Carmona A, Gutierrez RA, Doerner P: Arabidopsis TCP20 links regulation of growth and cell division control pathways. Proc Natl Acad Sci USA 2005, 102(36):12978-12983.

71. Fu X, Harberd NP: Auxin promotes Arabidopsis root growth by modulating gibberellin response. Nature 2003, 421(6924):740-743.

72. Kubo M, Udagawa M, Nishikubo N, Horiguchi G, Yamaguchi M, Ito J, Mimura T, Fukuda H, Demura T: Transcription switches for protoxylem and metaxylem vessel formation. Genes Dev 2005, 19(16):1855-1860.

73. Grant EH, Fujino T, Beers EP, Brunner AM: Characterization of NAC domain transcription factors implicated in control of vascular cell differentiation in Arabidopsis and Populus. Planta 2010, 232(2):337-352.

74. Gardiner J, Sherr I, Scarpella E: Expression of DOF genes identifies early stages of vascular development in Arabidopsis leaves. Int J Dev Biol 2010, 54(8-9):1389-1396.

75. Lee HW, Kim NY, Lee DJ, Kim J: LBD18/ASL20 regulates lateral root formation in combination with LBD16/ASL18 downstream of ARF7 and ARF19 in Arabidopsis. Plant Physiol 2009, 151(3):1377-1389.

76. Zhong $\mathrm{R}$, Richardson EA, Ye ZH: The MYB46 transcription factor is a direct target of SND1 and regulates secondary wall biosynthesis in Arabidopsis. Plant Cell 2007, 19(9):2776-2792.

77. Raynaud C, Sozzani R, Glab N, Domenichini S, Perennes C, Cella R, Kondorosi E, Bergounioux C: Two cell-cycle regulated SET-domain proteins interact with proliferating cell nuclear antigen (PCNA) in Arabidopsis. Plant J 2006, 47(3):395-407

78. Sozzani R, Maggio C, Giordo R, Umana E, Ascencio-lbañez JT, HanleyBowdoin L, Bergounioux C, Cella R, Albani D: The E2FD/DEL2 factor is a component of a regulatory network controlling cell proliferation and development in Arabidopsis. Plant Molecular Biology 2009, 72(4-5):381-395.

79. Menges M, Hennig L, Gruissem W, Murray JA: Cell cycle-regulated gene expression in Arabidopsis. J Biol Chem 2002, 277(44):41987-42002.

80. Kim JH, Kende $\mathrm{H}$ : A transcriptional coactivator, AtGIF1, is involved in regulating leaf growth and morphology in Arabidopsis. Proc Natl Acad Sci USA 2004, 101(36):13374-13379.

81. Kim JH, Choi D, Kende $\mathrm{H}$ : The AtGRF family of putative transcription factors is involved in leaf and cotyledon growth in Arabidopsis. Plant J 2003, 36(1):94-104.

82. Zhao Y, Medrano L, Ohashi K, Fletcher JC, Yu H, Sakai H, Meyerowitz EM: HANABA TARANU is a GATA transcription factor that regulates shoot apical meristem and flower development in Arabidopsis. Plant Cell 2004, 16(10):2586-2600.

83. d'Erfurth I, Jolivet S, Froger N, Catrice O, Novatchkova M, Simon M, Jenczewski E, Mercier R: Mutations in AtPS1 (Arabidopsis thaliana parallel spindle 1) lead to the production of diploid pollen grains. PLOS Genet 2008, 4(11):e1000274.

84. Sehnke PC, Laughner BJ, Lyerly Linebarger CR, Gurley WB, Ferl RJ: Identification and characterization of GIP1, an Arabidopsis thaliana protein that enhances the DNA binding affinity and reduces the oligomeric state of G-box binding factors. Cell Res 2005, 15(8):567-575.

85. Jiang H, Li H, Bu Q, Li C: The RHA2a-interacting proteins ANAC019 and ANAC055 may play a dual role in regulating $A B A$ response and jasmonate response. Plant Signal Behav 2009, 4(5):464-466.

86. Olsson AS, Engstrom P, Soderman E: The homeobox genes ATHB12 and ATHB7 encode potential regulators of growth in response to water deficit in Arabidopsis. Plant Mol Biol 2004, 55(5):663-677.

87. Tran LS, Nakashima K, Sakuma Y, Simpson SD, Fujita Y, Maruyama K, Fujita M, Seki M, Shinozaki K, Yamaguchi-Shinozaki K: Isolation and functional analysis of Arabidopsis stress-inducible NAC transcription factors that bind to a drought-responsive cis-element in the early responsive to dehydration stress 1 promoter. Plant Cell 2004, 16(9):2481-2498.

88. Leonhardt N, Kwak JM, Robert N, Waner D, Leonhardt G, Schroeder Jl: Microarray expression analyses of Arabidopsis guard cells and isolation of a recessive abscisic acid hypersensitive protein phosphatase $2 \mathrm{C}$ mutant. Plant Cell 2004, 16(3):596-615.

89. Oda $Y$, Yoshimura $Y$, Ohnishi H, Tadokoro M, Katsube $Y$, Sasao M, Kubo Y, Hattori K, Saito S, Horimoto K, et al: Induction of pluripotent stem cells from human third molar mesenchymal stromal cells. J Biol Chem 2010, 285(38):29270-29278.

90. Masip M, Veiga A, Izpisua Belmonte JC, Simon C: Reprogramming with defined factors: from induced pluripotency to induced transdifferentiation. Mol Hum Reprod 2010, 16(11):856-868.

91. Kotlyar M, Fuhrman S, Ableson A, Somogyi R: Spearman correlation identifies statistically significant gene expression clusters in spinal cord development and injury. Neurochem Res 2002, 27(10):1133-1140.

92. Spearman C: The proof and measurement of association between two things. American Journal of Psychology 1904, 15:72-101.

93. Irizarry RA, Hobbs B, Collin F, Beazer-Barclay YD, Antonellis KJ, Scherf U, Speed TP: Exploration, normalization, and summaries of high density oligonucleotide array probe level data. Biostatistics 2003, 4(2):249-264.

94. Redman JC, Haas BJ, Tanimoto G, Town CD: Development and evaluation of an Arabidopsis whole genome Affymetrix probe array. Plant J 2004, 38(3):545-561

95. Persson S, Wei H, Milne J, Page GP, Somerville CR: Identification of genes required for cellulose synthesis by regression analysis of public microarray data sets. Proc Natl Acad Sci USA 2005, 102(24):8633-8638.

96. Boyer LA, Lee TI, Cole MF, Johnstone SE, Levine SS, Zucker JP, Guenther MG, Kumar RM, Murray HL, Jenner RG, et al: Core transcriptional regulatory circuitry in human embryonic stem cells. Cell 2005, 122(6):947-956.

97. Aasen T, Raya A, Barrero MJ, Garreta E, Consiglio A, Gonzalez F, Vassena R, Bilic J, Pekarik V, Tiscornia $G$, et al: Efficient and rapid generation of induced pluripotent stem cells from human keratinocytes. Nat Biotechnol 2008, 26(11):1276-1284.

98. Monk M, Hitchins M, Hawes S: Differential expression of the embryo/ cancer gene ECSA(DPPA2), the cancer/testis gene BORIS and the pluripotency structural gene OCT4, in human preimplantation development. Mol Hum Reprod 2008, 14(6):347-355.

99. Isono K, Fujimura Y, Shinga J, Yamaki M, J OW, Takihara Y, Murahashi $Y$, Takada Y, Mizutani-Koseki Y, Koseki H: Mammalian polyhomeotic homologues Phc2 and Phc1 act in synergy to mediate polycomb repression of Hox genes. Mol Cell Biol 2005, 25(15):6694-6706.

100. Zwaka TP: Breathing chromatin in pluripotent stem cells. Dev Cell 2006 10(1):1-2.

101. Hirabayashi $Y$, Itoh $Y$, Tabata H, Nakajima K, Akiyama T, Masuyama N, Gotoh Y: The Wnt/beta-catenin pathway directs neuronal differentiation of cortical neural precursor cells. Development 2004, 131(12):2791-2801.

102. Murata Y, Doi T, Taniguchi H, Fujiyoshi Y: Proteomic analysis revealed a novel synaptic proline-rich membrane protein (PRR7) associated with PSD-95 and NMDA receptor. Biochem Biophys Res Commun 2005, 327(1):183-191.

103. Elms $P$, Siggers $P$, Napper $D$, Greenfield A, Arkell R: Zic2 is required for neural crest formation and hindbrain patterning during mouse development. Dev Biol 2003, 264(2):391-406.

104. Shuai B, Reynaga-Pena CG, Springer PS: The lateral organ boundaries gene defines a novel, plant-specific gene family. Plant Physiol 2002, 129(2):747-761.

105. Gan Y, Yu H, Peng J, Broun P: Genetic and molecular regulation by DELLA proteins of trichome development in Arabidopsis. Plant Physiol 2007, 145(3):1031-1042.

106. Ishida $T$, Hattori $S$, Sano $R$, Inoue $K$, Shirano $Y$, Hayashi $H$, Shibata $D$, Sato $S$, Kato T, Tabata $S$, et al: Arabidopsis TRANSPARENT TESTA GLABRA2 is directly regulated by $R 2 R 3$ MYB transcription factors and is involved in regulation of GLABRA2 transcription in epidermal differentiation. Plant Cell 2007, 19(8):2531-2543.

107. Kares C, Prinsen E, Van Onckelen H, Otten L: IAA synthesis and root induction with iaa genes under heat shock promoter control. Plant $\mathrm{Mol}$ Biol 1990, 15(2):225-236. 
108. Petersson SV, Johansson Al, Kowalczyk M, Makoveychuk A, Wang JY, Moritz T, Grebe M, Benfey PN, Sandberg G, Ljung K: An auxin gradient and maximum in the Arabidopsis root apex shown by high-resolution cellspecific analysis of IAA distribution and synthesis. Plant Cell 2009, 21(6):1659-1668.

109. Zhong R, Lee C, Zhou J, McCarthy RL, Ye ZH: A battery of transcription factors involved in the regulation of secondary cell wall biosynthesis in Arabidopsis. Plant Cell 2008, 20(10):2763-2782.

110. Ohashi-lto K, Bergmann DC: Regulation of the Arabidopsis root vascular initial population by LONESOME HIGHWAY. Development 2007, 134(16):2959-2968.

111. Li Y, Zheng L, Corke F, Smith C, Bevan MW: Control of final seed and organ size by the DA1 gene family in Arabidopsis thaliana. Genes Dev 2008, 22(10):1331-1336.

112. Bureau M, Rast MI, IIImer J, Simon R: JAGGED LATERAL ORGAN (JLO) controls auxin dependent patterning during development of the Arabidopsis embryo and root. Plant Mol Biol 2010, 74(4-5):479-491.

113. Ohashi K: [HANABA TARANU, a GATA transcription factor which affects shoot apical meristem development]. Seikagaku 2006, 78(9):888-891.

114. Yoshida T, Fujita Y, Sayama H, Kidokoro S, Maruyama K, Mizoi J, Shinozaki K, Yamaguchi-Shinozaki K: AREB1, AREB2, and ABF3 are master transcription factors that cooperatively regulate $A B R E-$ dependent $A B A$ signaling involved in drought stress tolerance and require $A B A$ for full activation. Plant J 2010, 61(4):672-685.

115. Rizhsky L, Liang H, Shuman J, Shulaev V, Davletova S, Mittler R: When defense pathways collide. The response of Arabidopsis to a combination of drought and heat stress. Plant Physiol 2004, 134(4):1683-1696.

116. Binder BM, Walker JM, Gagne JM, Emborg TJ, Hemmann G, Bleecker AB, Vierstra RD: The Arabidopsis EIN3 binding F-Box proteins EBF1 and EBF2 have distinct but overlapping roles in ethylene signaling. Plant Cell 2007, 19(2):509-523.

117. Thomas PQ, Johnson BV, Rathjen J, Rathjen PD: Sequence, genomic organization, and expression of the novel homeobox gene Hesx1. J Biol Chem 1995, 270(8):3869-3875.

118. Ezashi T, Ghosh D, Roberts RM: Repression of Ets-2-induced transactivation of the tau interferon promoter by Oct-4. Mol Cell Biol 2001, 21(23):7883-7891.

doi:10.1186/1752-0509-5-53

Cite this article as: Nie et al:: TF-Cluster: A pipeline for identifying functionally coordinated transcription factors via network decomposition of the shared coexpression connectivity matrix (SCCM). BMC Systems Biology 2011 5:53.

\section{Submit your next manuscript to BioMed Central and take full advantage of:}

- Convenient online submission

- Thorough peer review

- No space constraints or color figure charges

- Immediate publication on acceptance

- Inclusion in PubMed, CAS, Scopus and Google Scholar

- Research which is freely available for redistribution 